\title{
The amphetamine sensitization model of schizophrenia Relevance beyond psychotic symptoms?
}

\section{Review Article}

Author(s):

Peleg-Raibstein, Daria; Yee, Benjamin K.; Feldon, Joram; Hauser, Jonas

Publication date:

2009-11

Permanent link:

https://doi.org/10.3929/ethz-b-000018975

Rights / license:

In Copyright - Non-Commercial Use Permitted

Originally published in:

Psychopharmacology 206(4), https://doi.org/10.1007/s00213-009-1514-7 


\title{
The amphetamine sensitization model of schizophrenia: relevance beyond psychotic symptoms?
}

\author{
Daria Peleg-Raibstein • Benjamin K. Yee • \\ Joram Feldon • Jonas Hauser
}

Received: 4 December 2008 / Accepted: 10 March 2009/Published online: 27 March 2009

(C) Springer-Verlag 2009

\begin{abstract}
Rationale A sensitized dopamine system may be linked to the genesis of psychotic symptoms in schizophrenia. Following withdrawal from amphetamine exposures, psychotic-like traits have been robustly demonstrated, but the presence of cognitive/mnemonic deficits remains uncertain.

Methods Adult male Lewis and Fischer rats, differing in cognitive performance, were exposed intermittently to escalating doses of amphetamine over 5 weeks. This was effective in producing behavioral sensitization to a subsequent amphetamine challenge. Following 27 days of drug withdrawal, the animals were assessed in Pavlovian conditioning, object recognition, and spatial working memory. In addition, prepulse inhibition (PPI), spontaneous motor activity, and anxiety-like behavior were measured.

Results Amphetamine pretreatment induced behavioral sensitization in both rat strains similarly. Working memory was enhanced in Fischer but not Lewis rats following withdrawal. Spontaneous novel object preference was enhanced in sensitized Fischer rats, but was impaired in sensitized Lewis rats, thus effectively reversing the strain difference in non-sensitized controls. In contrast, Pavlovian fear conditioning remained unaffected and so were anxietylike behavior, open field activity, and PPI.

Conclusion The face validity of the amphetamine withdrawal model for cognitive deficits was limited to the
\end{abstract}

D. Peleg-Raibstein $(\bowtie) \cdot$ B. K. Yee $\cdot$ J. Feldon $\cdot$ J. Hauser

Laboratory of Behavioural Neurobiology,

Federal Institute of Technology Zurich,

Schorenstrasse 16,

Schwerzenbach 8603, Switzerland

e-mail: daria.peleg@behav.biol.ethz.ch object recognition memory impairment observed in sensitized Lewis rats. Yet, the possibility that enhancing dopaminergic neurotransmission may facilitate object recognition and spatial working memory performance was demonstrated in sensitized Fischer rats. Identification of the mechanisms underlying such strain-dependent effects would be instrumental in the further specifications of the construct validity, and therefore the limitations and potential of the amphetamine sensitization model of schizophrenia.

Keywords Amphetamine - Cognitive symptoms .

Dopamine $\cdot$ Psychosis $\cdot$ Schizophrenia $\cdot$ Sensitization

\section{Introduction}

Pharmacological sensitization refers to the enhancement or intensification of the specific response to a drug following prior exposure to the same (or functionally similar) drug. Sensitization of the motor responses to systemic amphetamine - a dopamine releaser - has been very well documented in rodents (for review, see Robinson and Becker 1986), and it has been studied in the context of drug addiction and schizophrenia (Kalivas et al. 1993; Nestler 2001; Robinson and Becker 1986). Support for its construct validity as a potential animal model for some aspects of schizophrenia includes recent neuroimaging reports which demonstrate enhanced striatal dopamine release induced by an acute amphetamine challenge in first-episode schizophrenia patients relative to healthy controls (Abi-Dargham et al. 1998; Breier et al. 1997; Laruelle 2000). It is further linked to an overexpression of mesolimbic dopamine $\mathrm{D}_{2}$ receptors in the patients (Abi-Dargham et al. 2000; Laruelle 1998; Wong et al. 1986). These findings have led to the "endogenous sensitization" hypothesis of schizophrenia, 
which postulates that a sensitized dopamine system is intrinsic to the disease and is responsible for the genesis of psychotic symptoms (Abi-Dargham et al. 1998; Breier et al. 1997; Laruelle 2000; Lieberman et al. 1997).

Repeated systemic amphetamine administrations in rodents not only result in an enduring sensitized response to a subsequent amphetamine challenge, they are also associated with changes in brain and behavior that are particularly pronounced following a prolonged period of abstinence or withdrawal (Paulson et al. 1991). The withdrawal period thus represents a drug-free but altered brain state that may better mimic the situations in schizophrenia patients than the use of acute amphetamine treatment in animals. Studies of amphetamine withdrawal have yielded evidence for the presence of behavioral dysfunctions relevant to schizophrenia in the absence of further drug challenge, including deficits in latent inhibition (LI) and prepulse inhibition (PPI) (Peleg-Raibstein et al. 2008; Peleg-Raibstein et al. 2006a; Peleg-Raibstein et al. 2006b; Russig et al. 2005; Tenn et al. 2003). LI and PPI deficits have been reported in schizophrenia patients and have been linked to an underlying impairment in selective attention and sensorimotor gating, respectively (Feldon and Weiner 1992; Geyer et al. 2001; Gray et al. 1991; Swerdlow et al. 2000).

The amphetamine withdrawal state is also associated with a variety of behavioral, molecular, neuroanatomical, and neurochemical adaptations in rodents and primates beyond the striatal dopaminergic system (Castner et al. 2005; Fletcher et al. 2005; Kolb et al. 2003; Peleg-Raibstein et al. 2008; Sokolov et al. 2003; Wolf 2003), suggesting that its application may extend beyond the modeling of dopaminergic dysfunction that is more closely linked to the psychotic symptoms of the disease. Schizophrenic patients also suffer from a variety of cognitive impairments, including deficits in working memory (Goldman-Rakic 1994; Weinberger and Gallhofer 1997), episodic memory, attention, cognitive flexibility, and executive functioning (Elvevag and Goldberg 2000; Gold et al. 1997; Goldberg et al. 1987, 1998; Pantelis et al. 1999; Pantelis et al. 2004). Indeed, the persistence and resistance to medication of such cognitive symptoms has been recognized as a major barrier impeding the effective social rehabilitation of schizophrenia patients (Braff and Light 2004; Green and Nuechterlein 1999).

Attempts to identify the presence of such cognitive and information processing deficits during amphetamine withdrawal in rats have yielded somewhat mixed but still encouraging outcomes. Two studies have thus far failed to show any clear changes in working memory function in animals undergoing amphetamine withdrawal (Featherstone et al. 2008; Stefani and Moghaddam 2002), while one study showed that amphetamine sensitization led to enhanced reversal in spatial learning in the water maze (Russig et al. 2003), which may instead be suggestive of a possible enhancing effect in working memory. The finding of Russig et al. (2003) is in keeping with the finding in LI (see above), but disagrees with reports of impairment in attentional set shifting (Featherstone et al. 2008; Fletcher et al. 2005) and visual attention (Fletcher et al. 2007). Clarification of the face validity of the amphetamine withdrawal models with respect to cognitive symptoms is therefore warranted, given the increasing clinical awareness of this symptom category (Green 2006; Green and Nuechterlein 1999).

Amphetamine-induced behavioral modification can vary considerably between strains (e.g., Alexander et al. 1996). Here, we examined the impacts of amphetamine withdrawal on cognitive function in a comparison between Fischer 344 and Lewis rats because their behavioral and neurochemical responses to drugs of abuse are known to markedly differ (for a review, see Kosten and Ambrosio 2002), suggesting a difference in dopaminergic function that may lead to divergent outcomes following repeated amphetamine pretreatment. In particular, the marked differences in cognitive and executive functions documented between these two rat strains (Pryce et al. 1999; Stohr et al. 1998b, 2000; van der Staay and Blokland 1996) fit our present focus on the cognitive impacts following amphetamine withdrawal. To this end, we conducted here various mnemonic tests, assessing associative learning, object recognition memory, and water maze learning. The relatively poor performance in these tests expected in Fischer rats would also facilitate the detection of any possible performance-enhancing effect of amphetamine withdrawal. Such possibility could be indicated by amphetamine-induced enhancement in working memory similar to the effects seen in Russig et al. (2003). In addition, tests of anxiety-related traits and spontaneous open field locomotor/explorative activity were conducted to identify possible confounds in data interpretation. In view of the suggestion that PPI disruption may provide an index of cognitive deterioration in schizophrenia patients (Geyer 2006), we also evaluated PPI here. The specific escalating amphetamine regimen (intermittent escalating doses from 1 to $5 \mathrm{mg}$ across 5 weeks) adopted here originates from Fletcher and colleagues, who reported its efficacy produce PPI disruption as well as some cognitive deficits in Sprague-Dawley rats (Featherstone et al. 2008; Fletcher et al. 2005; Tenn et al. 2003), which may be more effective than the escalating amphetamine regime (escalating doses from 1 to $5 \mathrm{mg}$ across 6 days) examined by us (Murphy et al. 2001; Peleg-Raibstein et al. 2006a; Russig et al. 2002, 2003, 2005). At the end of the study, behavioral sensitization to the motor stimulant effect of a subsequent amphetamine challenge was confirmed in a subset of animals from both strains. 


\section{Materials and methods}

Subjects

Naive male adult Fischer (F344/NHsd) and Lewis (LEW/ HANRijHsd) rats obtained from Harlan (Borchen, Germany) were first acclimatized to our laboratory housing facilities for 2 weeks before drug treatment began. The rats were housed individually under a reversed light-dark cycle (lights on 1900-0700 h) with controlled temperature $(21 \pm$ $\left.1^{\circ} \mathrm{C}\right)$ and humidity $(55 \pm 5 \%)$ conditions. Access to food and water was provided ad libitum throughout the entire experiment, with all tests carried out in the dark phase of the cycle. Rats were handled daily for 5 days prior to amphetamine pretreatment. Following the final amphetamine/saline pretreatment injection, all subjects were left completely undisturbed in their home cages until the commencement of behavioral evaluation on withdrawal day 27. The animals were subjected to multiple behavioral tests as detailed in Fig. 1. However, only a random half of the subjects in each treatment condition underwent the fear conditioning test, and in a further random selection (balanced across treatment conditions), 16 subjects were evaluated for the expression of behavioral sensitization to amphetamine. All procedures carried out on the animals had been previously approved by the Zurich Cantonal Veterinary Office, in accordance with the Animal Protection Act of Switzerland (1978), the European Council Directives 86/609/EEC on animal experimentation (1986), and the Principles of Laboratory Animal Care (NIH publication No. 86-23, revised 1985).

Drugs and pretreatment

D-Amphetamine sulfate (Sigma Chemical Company, St. Louis, USA) was dissolved in a $0.9 \% \mathrm{NaCl}$ solution to obtain the required concentrations of $1-5 \mathrm{mg} / \mathrm{ml}$. All the solutions were freshly prepared and administered in a volume of $1 \mathrm{ml} / \mathrm{kg}$ via the intraperitoneal route. The rats were randomly assigned to either the saline or amphetamine group and received accordingly either one amphetamine or one saline injection on 3 days per week (Monday, Wednesday, and Friday) for five consecutive weeks. The doses of amphetamine were increased from 1 to $5 \mathrm{mg} / \mathrm{kg}$, in increments of $+1 \mathrm{mg} / \mathrm{kg}$ every week. Immediately after the injection, each rat was returned to its home cage.

\section{Elevated plus maze test of anxiety}

On withdrawal day 27 , the rats were tested in the elevated plus maze as previously described (Russig et al. 2005). The test lasted $5 \mathrm{~min}$ and began with a rat being placed on the central platform, the head facing an open arm. An Ethovision tracking system (Version 3.1, Noldus Technology, The Netherlands) calculated the total distance moved and the time spent in each arm. The distance moved was used as an index of locomotion; the ratio of time spent in the open arms to total time spent in all four arms was used

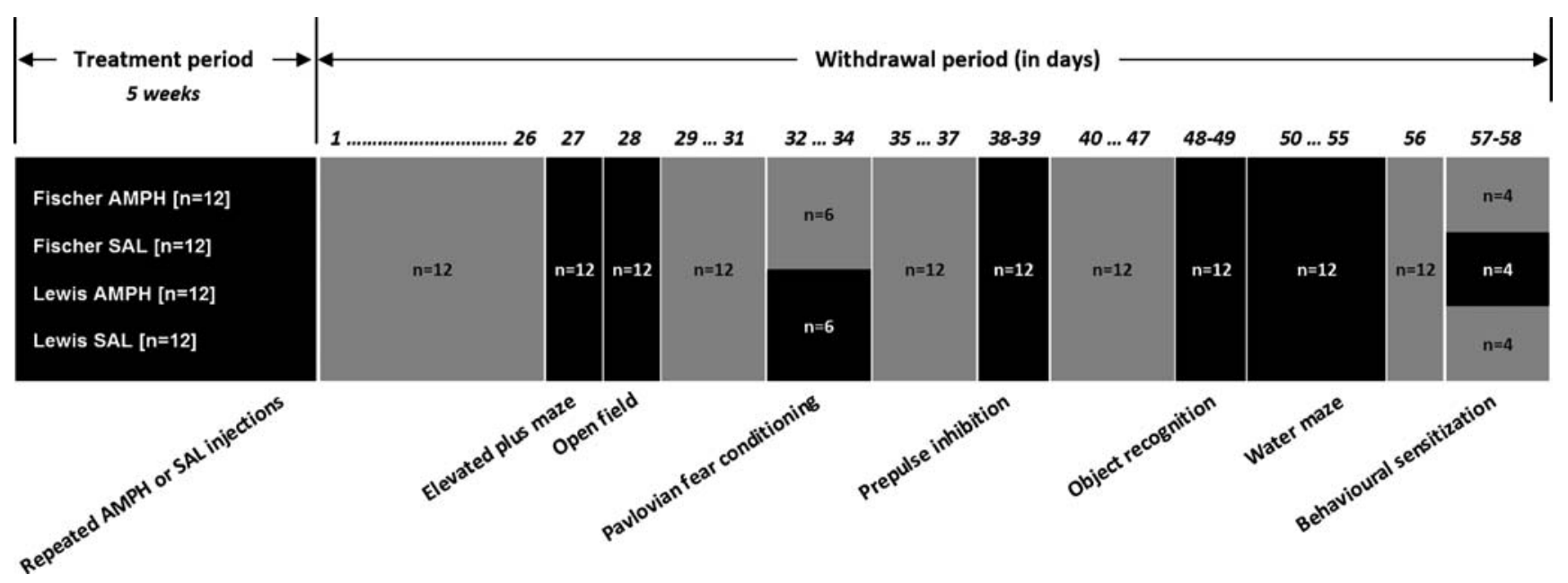

Fig. 1 Schematic illustration of the sequence of the behavioral tests performed. The behavioral test schedule, with exact withdrawal days and number of animals used per strain (Fischer and Lewis) and per pretreatment (amphetamine and saline). Gray box indicates a manipulation free period; the animals were left undisturbed in their home cages. Black box indicates the specific test the animals underwent. The fear conditioning experiment was originally planned to run as two replications. Given that the first cohort (with half of the subjects) was sufficient to generate a clear outcome, we refrained from further testing of the second cohort on ethical grounds. In order to complete the behavioral sensitization experiment on precisely the same withdrawal day, only a balanced cohort of 16 animals was evaluated, this being the maximum capacity of our long-term locomotor activity monitor system 
as an index of anxiety. The maze was cleaned with ethanol $15 \%$ and allowed to dry after each trial.

Open field test of spontaneous locomotor activity and explorative behavior

This was conducted on withdrawal day 28 using four identical gray acrylic open field arenas as fully described elsewhere (Stohr et al. 1998b). The distance traversed in the arena was measured using the Ethovision tracking system. Each trial lasted for $30 \mathrm{~min}$ and began with an animal being placed in the center of each arena. The subjects were tested in squads of four, with pretreatment and strain counterbalanced across the four open field arenas. These were cleaned with ethanol $15 \%$ and allowed to dry after each test.

\section{Pavlovian conditioned freezing}

This began on withdrawal day 32, using two sets of four Coulbourn operant conditioning chambers (Coulbourn Instruments, Allentown, PA, USA), which have previously been described in full (Richmond et al. 1998). Each chamber was housed inside a ventilated and soundattenuated chest. One set (context A) was used for conditioning and test of conditioned context freezing and was equipped with a shock-administering grid floor (Model no. E10-10RF) in each chamber. The other set (context B) was used for test of conditioned tone freezing. The two sets of context differed in terms of the grid mesh design (A: bars, B: round holes), the shape of the Plexiglas enclosure (A: square B: round), and the level of illumination (A: dim light, B: infrared light).

Stimulus presentation was controlled by a Coulbourn Universal Environment Interface (model no. E91-12) and a Coulbourn Universal Environment Port (model no. L91-12). The discrete stimulus used was an $86-\mathrm{dB}_{\mathrm{A}}$ tone produced by a 2.9-kHz tone module (model E12-02) fixed in the wall of each test chamber, with indistinguishable acoustic characteristics between the two contexts. Shocks were delivered using a Coulbourn Precision Animal Shocker (model no. E13-12). During all testing sessions, background noise of $48 \mathrm{~dB}_{\mathrm{A}}$ was provided by a ventilation fan fixed to the outer chest of each chamber.

A miniature infrared-sensitive digital camera with a $2.5-\mathrm{mm}$ wide angle $\left(100^{\circ}\right)$ lens (CES AG, Zurich, Switzerland, VPC465B) and two infrared emitting diodes (Hewlett-Packard, Palo Alto, CA, USA; model no. HSDL-4220) were installed in each chamber. The cameras captured images at $1 \mathrm{~Hz}$ for transmission to a PC for image analysis and quantification of freezing. Comparison between successive frames taken at $1 \mathrm{~s}$ apart was performed according to the algorithm described by Richmond et al. (1998) and implemented on a PC running the WiT (version 5.3, DALSA, Waterloo,
Ontario, Canada) image analysis program controlled by a visual basic macro program prepared in-house (Peter Schmid). The number of pixels changed (defined as a change in brightness over $8 \%$ ) between successive frames was calculated. Freezing for the given 1-s interval was scored when the total number of pixels changed was less than $0.05 \%$ of the total pixels.

The experiment began with 1 day of apparatus habituation (context A), followed by conditioning, a context test, and a tone test, at $24 \mathrm{~h}$ intervals. On the conditioning day, all animals underwent ten trials of tone-shock pairings, administered at a fixed inter-trials interval (ITI) of $2 \mathrm{~min}$. Each conditioning trial began with a 9-s tone followed immediately by a 1 -s foot shock set at $0.5 \mathrm{~mA}$. On the next day (context test), the animals were returned to the shocked context (context A) and left undisturbed for $8 \mathrm{~min}$. On the last day, test of conditioned freezing to the tone was conducted in a novel context (context B), in which the animals were first left undisturbed in the apparatus for 3 min (pre-CS period) before the onset of the tone CS that remained on for $8 \mathrm{~min}$ (CS period).

\section{Prepulse inhibition}

The evaluation of PPI of the acoustic startle reflex was conducted on withdrawal days 38 and 39. The apparatus consisted of four sound-attenuated acoustic startle chambers (SR-LAB; San Diego Instruments, San Diego, CA, USA) as fully described before (Pothuizen et al. 2006). A constant $68-\mathrm{dB}_{\mathrm{A}}$ background noise was presented throughout the test session. Three different pulse intensities (at 100, 110, and $\left.120 \mathrm{~dB}_{\mathrm{A}}\right), 30 \mathrm{~ms}$ in duration, and three different prepulse intensities (at 74, 80, and $86 \mathrm{~dB}_{\mathrm{A}}$ ), which corresponded to $+6,+12$, and $+18 \mathrm{~dB}$ above background, respectively, $20 \mathrm{~ms}$ in duration were used. These allowed nine possible prepulse-and-pulse combinations. A stimulus onset asynchrony (SOA) of $100 \mathrm{~ms}$ between the two stimuli on prepulse-and-pulse trials was used throughout. In addition to the analysis of the reactivity score (following logarithmic transformation), PPI was also expressed as percent inhibition at each prepulse intensity by: \%PPI $=[$ (pulse-alone prepulse-and-pulse)/pulse-alone $\times 100 \%]$. Testing was completed in 2 days, with all between-subject factors fully counterbalanced across days and boxes.

\section{Object recognition}

This test was conducted on withdrawal days 48 and 49 using one of the open field arenas described above in a dimly lit testing room $(15 \mathrm{~lx})$. A video camera was mounted above the arena to allow digital recording of the session for subsequent data extraction. The test comprised two phases, sample phase and test phase, which were separated by one 
of two different retention intervals $(2 \mathrm{~min}$ or $15 \mathrm{~min}$, conducted on separate days). To begin the sample phase, two identical objects were placed at the two opposing corners (15 cm clear of the walls), and the subject was introduced to the arena center with its head facing one of the empty corners chosen at random. This phase lasted for $5 \mathrm{~min}$ and was followed by the retention interval. Next, the test phase began with one new copy of the sample (familiar) object placed in one of the two previously occupied corners and a copy of a novel object discriminandum (new) in the opposing corner. The relative placement of the novel and familiar objects was counterbalanced between subjects. The arena and objects were cleansed with $15 \%$ ethanol prior to each phase.

Four distinct objects, with three copies of each, were used as discriminanda for the experiment. They were: (a) brown plastic flower pots (average diameter $30 \mathrm{~cm}$, height $17.5 \mathrm{~cm}$ ), (b) white plastic boxes $(13.5 \times 8.5 \times 9 \mathrm{~cm})$, (c) transparent glass bottles (diameter $9.5 \mathrm{~cm}$, height $20 \mathrm{~cm}$ ), and (d) red bricks $(14 \times 9.7 \times 28.3 \mathrm{~cm})$. They were used as two fixed pairs: (a) vs. (b) and (c) vs. (d); one pair was used uniquely for each test day. The two test days differed in the delay interval between sample and test runs. The order of, and the combinations between, object pairs and delays were counterbalanced across the 2 days of testing within each group.

Because rodents have a natural preference for novel stimuli, the relative exploration time of the novel in comparison to the familiar discriminanda was used to index object recognition memory in the test phase. Exploration time was extracted by an experimenter under blind conditions with the assistance of the Observer software implemented on a handheld PSION computer (Workabout, London, UK).

Water maze test of spatial working memory

The water maze experiment was conducted on withdrawal days 50-55. The apparatus consisted of a circular fiberglass tank, painted black, measuring $2 \mathrm{~m}$ in diameter by $60 \mathrm{~cm}$ high, and positioned $40 \mathrm{~cm}$ above the floor in the middle of a well-lit testing room with several distal cues fixed on the room walls. It was filled with a mixture of fresh hot and cold tap water every day to a depth of $30 \mathrm{~cm}$ and maintained at $21 \pm 1^{\circ} \mathrm{C}$. A rough circular platform (diameter $11 \mathrm{~cm}$ ) submerged $2 \mathrm{~cm}$ below the water surface served as the escape platform. A visual cue (circular white disk) could be mounted $11 \mathrm{~cm}$ above it, to provide a local cue for the platform location. A video camera was mounted directly above the maze and connected to a PC running the Ethovision ${ }^{\circledR}$ tracking system (Noldus Information Technology, Wageningen, The Netherlands). Four equally spaced points along the circumference of the maze were arbitrarily assigned as $\mathrm{N}, \mathrm{E}, \mathrm{S}$, and $\mathrm{W}$, to define four equal quadrants and different start locations.
On day 1 , the animals were trained on a visually guided task in two trials in which the platform was located in the middle of the maze and marked by the local cue. To begin each trial, the animals were released from the starting point and allowed $90 \mathrm{~s}$ within which to escape onto the platform. If a rat failed to locate the platform, it was guided to it by the experimenter. The starting points for the two trials were always $180^{\circ}$ apart: either $\mathrm{N}$ and $\mathrm{S}$, or $\mathrm{E}$ and $\mathrm{W}$, with these two possibilities counterbalanced with respect to all between-subject factors.

The working memory test took place over the next 5 days, with two test sessions conducted on each day, separated by $4 \mathrm{~h}$ during which the rats were returned to their home cage. The platform location was switched between sessions, but remained unchanged across the two trials of a given session. Eight possible platform positions were defined $(50 \mathrm{~cm}$ off the wall in each of the directions N, NE, E, SE, S, SW, W, and NW), and each position was used once in the first eight sessions, before the first two locations were repeated on the last day. The different platform locations were counterbalanced across all between-subjects factors in each session. Trials 1 and 2 in a session were separated by a delay of $30 \mathrm{~s}$ (including $15 \mathrm{~s}$ spent on the platform), and working memory was indexed by improvement between the two trials. A total of eight possible starting positions were defined: N, E, S, W, NE, $\mathrm{SE}, \mathrm{SW}$, and NW, and across the two trials of a given session, the two starting positions were pseudorandomly chosen from the five possible starting positions furthest from the platform, with the condition that they must be at least $90^{\circ}$ apart.

\section{Activity measurement for assessment of locomotor} sensitization

The apparatus consisted of 16 chambers $(25 \times 40 \times 40 \mathrm{~cm})$ specially designed for long-term assessment of locomotor activity, which was measured by an image analysis algorithm as specified before. Activity scores were quantified into successive 20-min bins. Full details of the apparatus and hardware have been fully described in Russig et al. (2002).

The subjects were moved to the apparatus at $1740 \mathrm{~h}$ on withdrawal day 57. At $0940 \mathrm{~h}$ on withdrawal day 58, a saline injection was given, and $1 \mathrm{~h}$ later, an amphetamine challenge (1 $\mathrm{mg} / \mathrm{kg}$, i.p.) was administered. The animals were observed for another $3 \mathrm{~h}$ before being removed from the chambers. The last hour before saline injection was taken as the baseline period, for comparison with the saline period $(1 \mathrm{~h})$ and the subsequent amphetamine period $(3 \mathrm{~h})$.

Statistical analysis

All statistical analyses were carried out using SPSS $^{\circledR}$ for Windows $^{\mathrm{TM}}$ (version 13). Parametric analyses of variance 
Table 1 Elevated plus maze (EPM) indexes of anxiety and locomotor activity

\begin{tabular}{|c|c|c|c|c|}
\hline \multirow[t]{2}{*}{ EPM dependent variables } & \multicolumn{2}{|l|}{ Fischer } & \multicolumn{2}{|l|}{ Lewis } \\
\hline & Amphetamine $(n=12)$ & Saline $(n=12)$ & Amphetamine $(n=12)$ & Saline $(n=12)$ \\
\hline Percent time in open arms & $28.2 \pm 6.6$ & $20.4 \pm 4.2$ & $20.5 \pm 3.8$ & $21.2 \pm 3.1$ \\
\hline Total distance traveled $(\mathrm{m})$ & $14.9 \pm 1.1$ & $16.8 \pm 0.8$ & $13.3 \pm 1.0$ & $15.2 \pm 1.1$ \\
\hline
\end{tabular}

Percentage time spent in the open arms (time in open arms/time in all four arms $\times 100$ ) was taken as an index of anxiety. Total distance moved was taken as an index of locomotor activity. Mean values are presented separately for strain and pretreatment with the standard error of the mean. The standard error for difference between means (SED) was 4.6 for the percentage time in open arms and 1.0 for total distance traveled.

(ANOVAs) of a split-plot (mixed) design consisting of the two following between-subject factors: strain and pretreatment, and appropriate within-subject factors as required by the data set in question (e.g., time bins, trials, objects, pulse and prepulse intensity, etc). Data interpretation was further assisted by the use of restricted ANOVAs for determining the locus of significant effects. The logarithmic transformation was applied to better conform to the normality assumption of parametric ANOVA whenever appropriate: PPI experiment (in pulse-alone, prepulse-alone and prepulse-and-pulse trials), water maze (path length and latency to reach the platform), and object recognition (time spent exploring the object).

\section{Results}

\section{Elevated plus maze}

On withdrawal day 27 , the animals were subjected to a test of anxiety using the elevated plus maze. There was no evidence for any significant strain difference or amphetamine pretreatment effect in anxiety-like behavior based on a $2 \times 2$ (strain $\times$ pretreatment) ANOVA of percent time spent in open arms (see Table 1). The interaction term also did not attain statistical significance $[F<1]$. The two strains also did not differ significantly in terms of locomotor activity, as indexed by total distance moved in the entire maze area (see Table 1). Amphetamine pretreatment had yielded a slight reduction in this measure that was similarly present in both strains. A separate ANOVA of total distance moved yielded no significant effect, although the main effect of pretreatment was close to statistical significance $[F$ $(1,44)=3.53, p=0.067]$. Again, the interaction term was far from statistical significance $[F<1]$.

\section{Open field}

On withdrawal day 28 , the open field was used to assess spontaneous locomotor activity and spatial exploration. There was a clear habituation effect of locomotor activity as evidenced by a reduction in distance moved across successive 5-min bins over the course of the 30-min test period, which was observed in both strains (Fig. 2). However, the two strains differed from each other at the beginning of the test when Lewis rats appeared to be more active. By the end of the test period, the activity levels of both Fischer and Lewis rats had reduced to a similar asymptotic level. These impressions were supported by a $2 \times 2 \times 6$ (strain $\times$ pretreatment $\times$ bins) split-plot ANOVA of distance traveled, which yielded a main effect of bins $[F(5$, $220)=61.14, p<0.001]$ and its interaction with strain $[F(5$, $220)=4.52, p<0.001]$, without the main effect of strain achieving statistical significance. Pair-wise comparisons between strains at successive bins only yielded significant differences in the first two bins $[p<0.05]$. Amphetamine pretreatment, on the other hand, did not appear to alter the overall activity level or the habitation of activity over time. Neither the main effect of pretreatment $[F(1$,
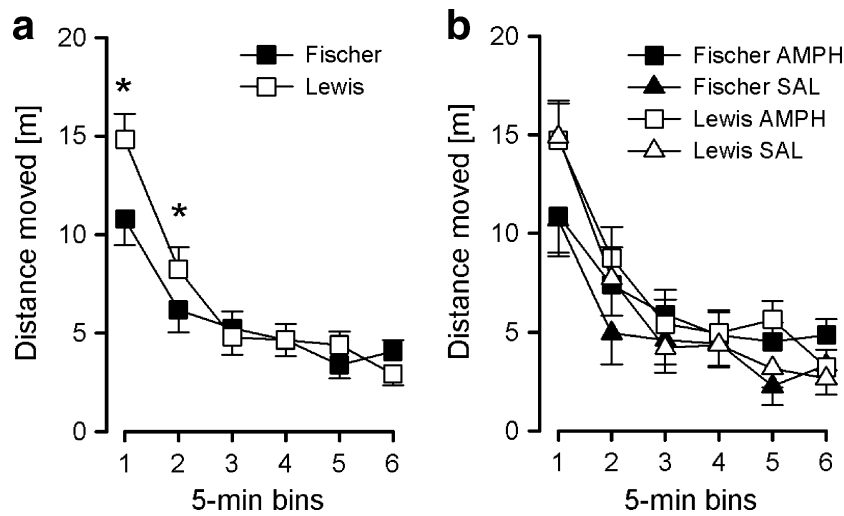

Fig. 2 Locomotor activity in the open field. Locomotor activity in the open field after 28 days of withdrawal in Fischer and Lewis rats pretreated with saline or amphetamine $(N=12$ per strain per pretreatment). The distance moved during the six 5-min bins (a) split by strain and (b) split by amphetamine pretreatment and strain. Locomotor habituation was observed in all subjects. An increased locomotor activity was observed in Lewis in the two first 5-min bins. All values are mean \pm standard error derived from the ANOVA. Asterisks refer to statistically significant differences between strains $(p<0.05)$ based on pair-wise comparisons performed on successive bins using the appropriate error variance associated with the significant strain $\times$ bins interaction in the overall ANOVA 
$44)=1.27, p<0.27]$ nor its interactions $[F$ 's $<1]$ attained statistical significance (data not shown).

\section{Conditioned freezing}

The conditioning day, context freezing test, and tone freezing test (conducted on withdrawal days 32, 33, and 34 , respectively) were separately analyzed. Within the conditioning day, freezing measures obtained in the CS and ITI periods were also separately analyzed.

Conditioning First, freezing response in the presence of the tone was assessed across the ten trials of tone-shock pairings (Fig. 3a). There was a rapid rise in freezing following the first CS presentation when freezing was almost absent. By the third presentation of the CS, response in both strains had reached a peak, and a clear strain difference emerged at the same time: Fischer rats exhibited a substantially lower level of freezing which lasted till the end of the session. These impressions were supported by a
$2 \times 2 \times 10$ (strain $\times$ pretreatment $\times$ trials) split-plot ANOVA of percent time freezing which yielded a main effect of trials $[F(9,396)=11.78, p<0.001]$, strain $[F(1,44)=18.41$, $p<0.001]$, and their interaction $[F(9,396)=2.45, p<0.01]$. Pair-wise comparisons between strains on successive trials indicated that the two strains differed significantly from the third trial onwards. Neither the factor pretreatment nor its interaction reached statistical significance, which is consistent with the impression that amphetamine pretreatment did not alter the overall freezing behavior or its development across trials (data not shown).

A highly similar pattern emerged from the freezing measures obtained in the ITI periods (Fig. 3b). There was a rapid rise in freezing from the beginning of the session, followed by the emergence of a strain difference in the same direction as described above. A $2 \times 2 \times 11$ (strain $\times$ pretreatment $\times$ ITI) split-plot ANOVA of percent time freezing per ITI period again yielded a main effect of ITI $[F$ $(10,200)=7.05, p<0.001]$, strain $[F(31,20)=31.40, p<$ $0.001]$, and their interaction $[F(10,200)=2.75, p<0.005]$.
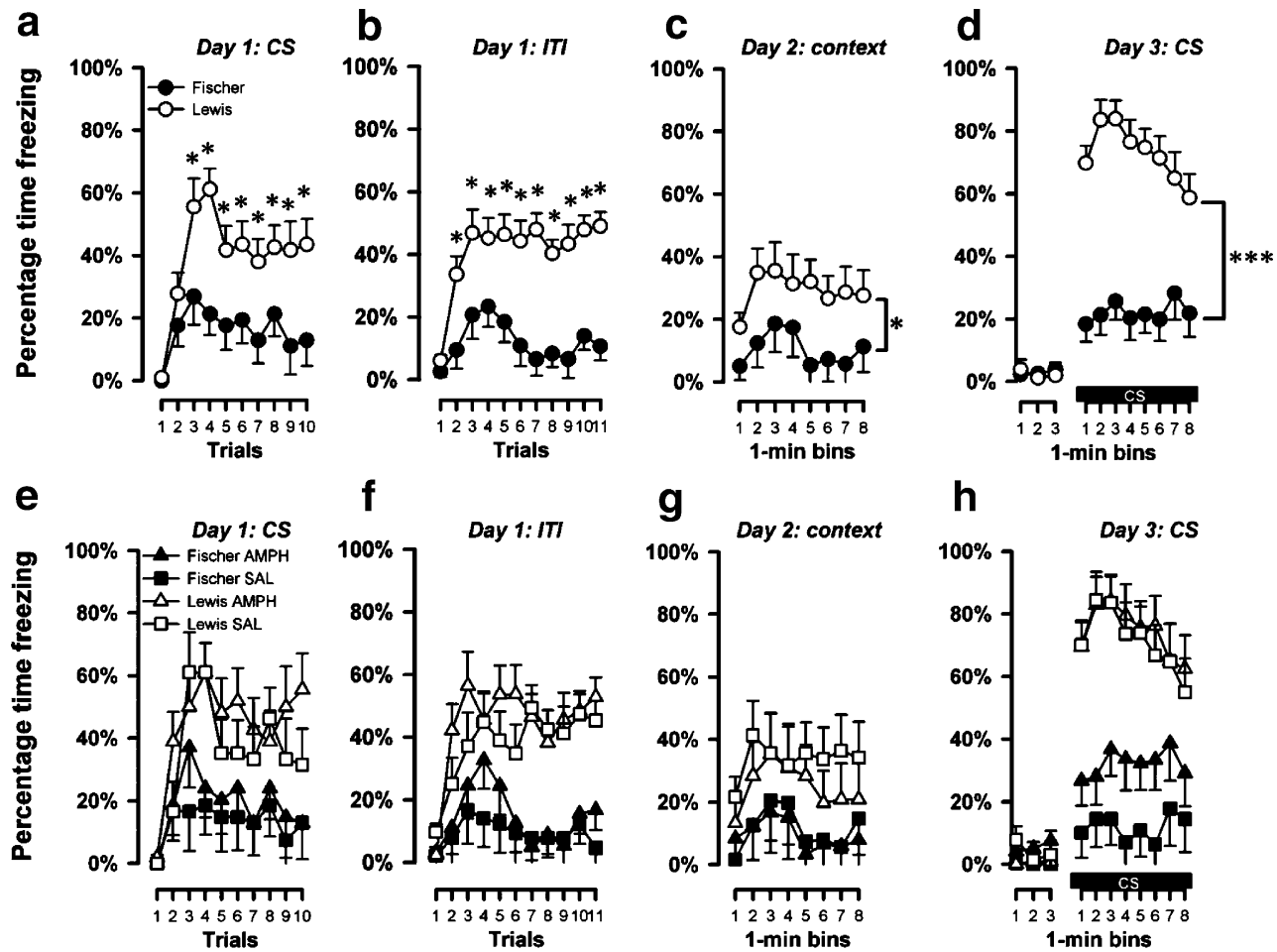

Fig. 3 Percentage time freezing during conditioning, context freezing, and tone freezing. Percentage time freezing in a Pavlovian tone-shock conditioning experiment after 32-34 days of withdrawal in Fischer and Lewis rats pretreated with saline or amphetamine $(N=6$ per strain per pretreatment). Percentage time freezing split by strain during: a the ten 9-s tone (CS) in the conditioning day (withdrawal day 32), b during the eleven 2-min ITIs (withdrawal day 32), c during the eight 1 -min bin of context freezing (withdrawal day 33), and d during the three 1-min bins preceding the CS onset and the eight 1-min bins of CS presentation of tone freezing (withdrawal day 34). $\mathbf{e}-\mathbf{h}$ The same percentage time freezing but split by pretreatment by strain. Lewis rats
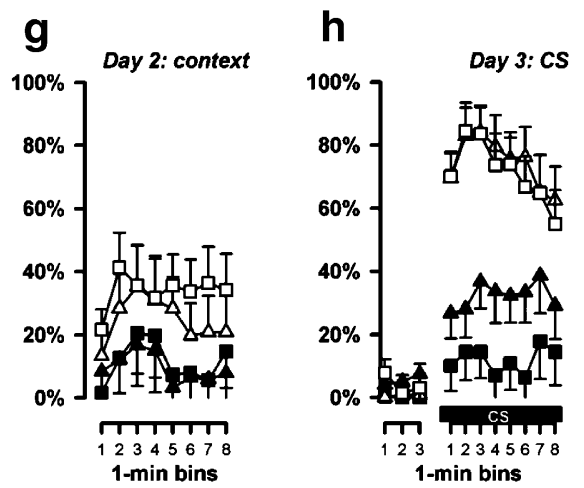

showed an increased freezing in the conditioning day both during the tone CS (from the third trial) and during the ITI (from the second trial), in context freezing (throughout the $8 \mathrm{~min}$ ) and in the tone freezing (throughout the $8 \mathrm{~min}$ of CS exposure). In the tone freezing, Lewis rats further presented extinction over time, which was not observed in Fischer rats. All values are mean \pm standard error derived from the ANOVA. Asterisks in (a), (b), (c), and (d) denote the significant $\left({ }^{*} p<0.05, *^{* *} p<0.001\right)$ main effect of strain based on pairwise comparisons performed on successive trials using the appropriate error variance associated with the significant strain $\times$ trials interaction in the overall ANOVA 
Pair-wise comparisons between strains at successive ITIs showed that the strain difference was significant from the second ITI onwards [all $p$ 's $<0.05]$. Again, amphetamine pretreatment was without any significant impact on this measure (data not shown).

Context freezing On the next day, the animals were returned to the shocked context and freezing behavior was evaluated for $8 \mathrm{~min}$ in the absence of any discrete stimulus. The two rat strains again differed similarly, with Fischer rats exhibiting low levels of freezing compared to Lewis rats throughout the 8 -min test period (Fig. 3b). This led to the emergence of a highly significant strain effect $[F(1,44)=52.97, p<0.001]$ from a $2 \times 2 \times 8$ (strain $\times$ pretreatment $\times 1$-min bins) splitplot ANOVA of percent time freezing. The levels of freezing also varied significantly across bins, yielding therefore also a significant effect of bins $[F(7,308)=$ $30.90, p<0.001]$. Pretreatment on the other hand had no significant impact on freezing behavior observed on this day; neither the main effect of pretreatment nor its interaction was close to statistical significance [all $F$ 's $<1$ ].

Tone freezing Baseline freezing behavior over the $3 \mathrm{~min}$ prior to the tone onset was generally low, and as expected, a $2 \times 2 \times 3$ (strain $\times$ pretreatment $\times 1$-min bins) split-plot ANOVA yielded no significant effect. During the presentation of the tone in the following $8 \mathrm{~min}$, Fischer rats again exhibited reduced freezing. This strain effect was sustained over the entire 8 -min CS period (Fig. 3c). These impressions were supported by a $2 \times 2 \times 8$ (strain $\times$ pretreatment $\times$ bins) split-plot ANOVA of percentage time freezing, which yielded a significant main effect of strain $[F(1,20)=38.71$, $p<0.001]$, bins $[F(7,140)=2.89, p<0.01]$, as well as their interaction $[F(7,140)=3.06, p<0.05]$. The interaction stemmed from the presence of an initial increase followed by an extinction profile over time in the Lewis but not in the Fischer rats. Supplementary analyses restricted to either strain confirmed this interpretation because a main effect of bins was only revealed in the Lewis strain $[F(7,70)=4.66$; $p<0.001]$. Consistent with the previous days, pretreatment had no significant impact on freezing behavior on this day: neither the main effect of pretreatment nor its interaction achieved statistical significance [all $p$ 's $>0.1$ ].

Prepulse inhibition

Prepulse inhibition expression was assessed on withdrawal day 38 or 39 . Five separate analyses were conducted to examine different aspects of performance in the PPI test.

Startle habituation Startle habituation was measured as the diminution of the startle response between the first and last block of trials that comprised only six pulse-alone trials (two trials per pulse intensity per block). A general habituation effect was detected in all groups and across all three pulse intensity levels. As expected, the startle reaction was proportional to the intensity of the pulse stimulus. The mean \pm standard error (SE) startle reaction (logarithmically transformed) across all subjects in the first and last blocks, at the three pulse intensities were as follows: $100 \mathrm{~dB}_{\mathrm{A}}$ : first $=$ $3.69 \pm .14$, last $=3.06 \pm 0.15 ; 110 \mathrm{~dB}_{\mathrm{A}}$ : first $=4.88 \pm 0.10$, last $=$ $4.44 \pm 0.13$; and $120 \mathrm{~dB}_{\mathrm{A}}$ : first $=5.39 \pm 0.11$, last $=4.94 \pm 0.13$. Neither strain nor pretreatment produced any significant effect on this measure (data not shown). A $2 \times 2 \times 2 \times 3$ (strain $\times$ pretreatment $\times$ blocks $\times$ pulse intensity) split-plot ANOVA of startle reactivity only revealed a significant main effect of blocks $[F(2,8)=187.16, p<0.001]$, and of pulse intensity $[F(1,44)=19.05, p<0.001]$. There was no significant main effect or interaction involving strain or pretreatment [all $p$ 's $>0.1]$.

Startle reactivity on pulse-alone trials It is essential to evaluate first the magnitude of the baseline acoustic startle response obtained on pulse-alone trials in the main middle blocks of the test session prior to the assessment of prepulse inhibition. In agreement with the startle habituation analysis described above, a $2 \times 2 \times 3$ (strain $\times$ pretreatment $\times$ pulse intensity) split-plot ANOVA of the reactivity score (logarithmically transformed) did not reveal any differences in pulse-alone trials due to either strain or pretreatment, but only a significant main effect of pulse intensity $[F(2,88)=$ $369.70, p<0.001]$. As expected, the startle response magnitude increased as a function of pulse intensity (Fig. $4 \mathrm{~d},+0 \mathrm{~dB}_{\mathrm{A}}$ prepulse intensity).

Percent PPI PPI refers to the attenuation of the startle response to a pulse stimulus when it is preceded by a prepulse. Given that acoustic startle response obtained on pulse-alone trials did not differ between strains or between pretreatment conditions, we first conducted an evaluation based on the conventional measure of PPI using percent inhibition: [\%PPI $=$ (pulse-alone - prepulse-and-pulse) $/$ (pulse-alone $\times 100 \%$ )]. This was calculated for each of the nine possible prepulse-and-pulse combinations. As shown in Fig. 4a, increasing prepulse intensity led to strong \%PPI in both Fischer and Lewis rats, with the Fischer rats showing a consistently weaker \%PPI. On the other hand, pretreatment did not lead to any appreciable differences in this measure of \%PPI (Fig. 4b). These impressions were confirmed by a $2 \times 2 \times 3 \times 3$ (strain $\times$ pretreatment $\times$ prepulse intensity $\times$ pulse intensity) split-plot ANOVA of \%PPI, which yielded a significant main effect of prepulse intensity $[F(2,88)=178.93, p<0.001]$ and of strain $[F(1,44)=12.04$, $p<0.005]$. The strain by pulse intensity interaction also achieved statistical significance $[F(2,88)=3.45, p<0.05]$, 

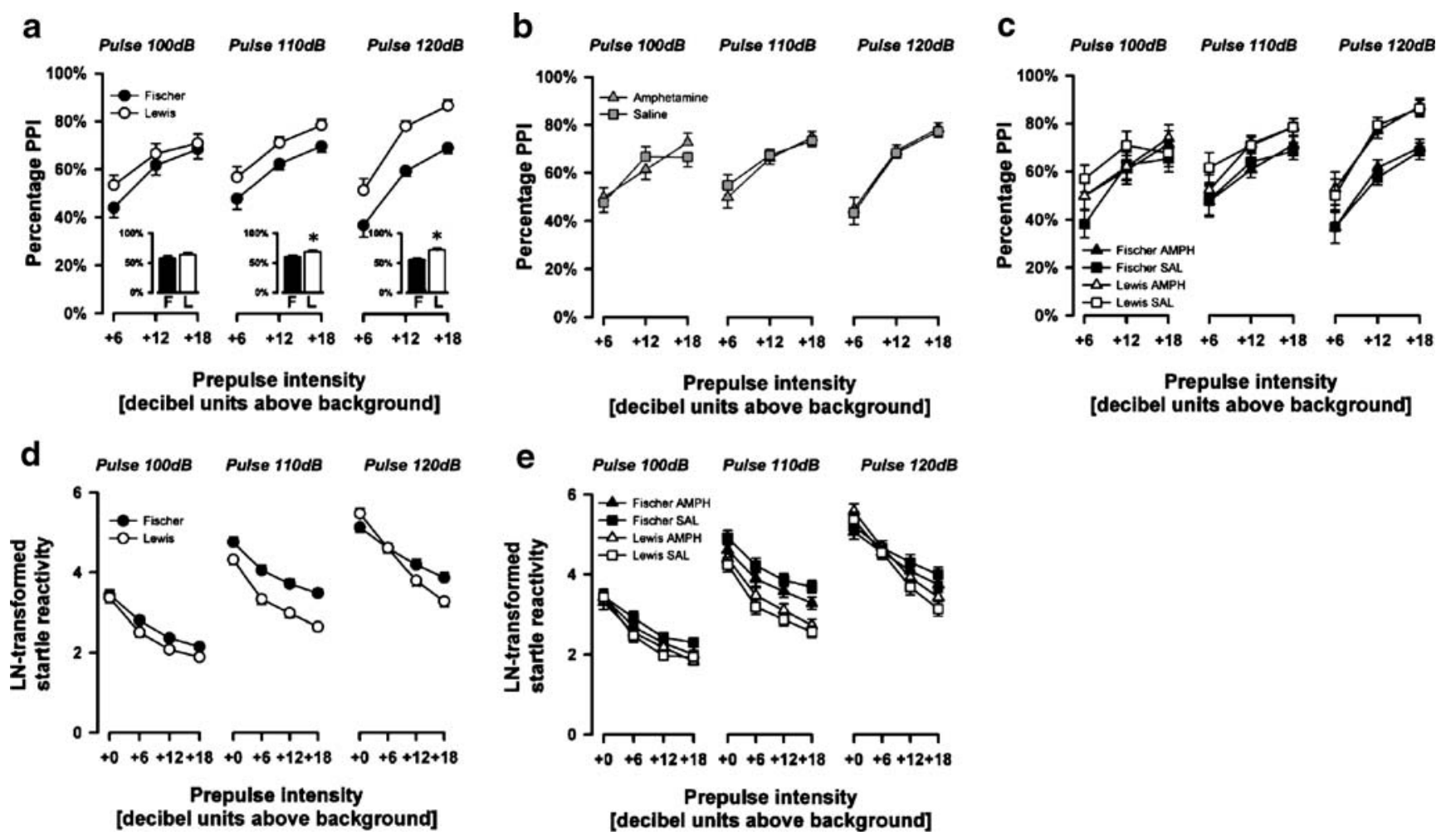

Fig. 4 Prepulse inhibition of the startle reactivity. Prepulse inhibition, expressed as percentage PPI or reactivity to the prepulse-and-pulse trials, was tested on withdrawal day 38 or 39 in Fischer (F) and Lewis (L) rats pretreated with saline or amphetamine $(N=12$ per strain per pretreatment). Percent PPI split by strain (a), by pretreatment (b), or by strain and by pretreatment (c) for each prepulse and pulse; reactivity to the prepulse-and-pulse trials split by strain (d), or by

suggesting that the strain difference in \%PPI was more pronounced with increasing pulse intensity. Separate analyses restricted to each pulse intensity showed that the main effect of strain achieved statistical significance only at pulse intensities of $110 \mathrm{~dB}[F(1,44)=6.46, p<0.05]$ and $120 \mathrm{~dB}$ $[F(1,44)=23.16, p<0.001]$. None of the analyses described revealed any significant effects of pretreatment or its interaction (Fig. 4c).

Prepulse-and-pulse trials reactivity The above impression of a pulse-dependent reduction of PPI expression in the Fischer relative to Lewis rats was confirmed by the analysis based on the startle reactivity magnitude obtained on pulsealone and prepulse-and-pulse trials. In this analysis, the magnitude of PPI is reflected by the slope of the individual reactivity curves depicted in Fig. $4 \mathrm{~d}$ and e. It can readily be seen that reactivity reduced with increasing prepulse intensity, regardless of pulse intensity and strains. The response to the presence of the prepulse stimulus was, however, weaker in the Fischer rats, as most obviously seen at the highest pulse intensity condition (pulse $=120 \mathrm{~dB}$ ), supporting the impression of a pulse intensity-dependent reduction of PPI in the Fischer rats identified in the \%PPI

strain and by pretreatment (e). Lewis rats showed increased PPI at the two higher pulse intensities compared to Fischer rats, in both \%PPI and prepulse-and-pulse reactivity. All values are mean \pm standard error derived from the ANOVA. Condition " +0 " represents the "nostimulus" condition in the test. Asterisks in (a) refer to statistical significant difference between strains $(p<0.05)$ based on restricted analyses conducted at each level of pulse intensity

analysis above. This is confirmed by the presence of the critical strain $\times$ prepulse intensity $\times$ pulse intensity interaction $[F(6,264)=3.31, p<0.005]$ in a $2 \times 2 \times 4 \times 3$ (strain $\times$ pretreatment $\times$ prepulse intensity $\times$ pulse intensity) split-plot ANOVA of startle reactivity (logarithmically transformed) across all pulse-alone and prepulse-and-pulse trials. Consistent with this interpretation, strain by prepulse intensity interaction $([F(3,132)=12.24, p<0.001]$ as well as a strain by pulse intensity interaction $[F(2,88)=15.57$, $p<0.001]$ also attained statistical significance. Restricted analysis applied to each pulse intensity condition revealed the presence of a strain by prepulse intensity interaction only in the conditions of pulse $=110 \mathrm{~dB}[F(3,132)=3.17, p<0.05]$ and of pulse $=120 \mathrm{~dB}[F(3,132)=16.22, p<0.001]$, but not at the lowest pulse intensity, thereby confirming the pulsedependent strain difference in the expression of PPI. Again, none of the analyses described revealed any significant effects of pretreatment or its interaction (Fig. 4e).

Direct reaction in prepulse-alone trials To examine the direct reaction elicited by the prepulse stimulus alone, the reactivity scores (logarithmically transformed) obtained in prepulse-alone trials as well as in no-stimulus trials were 
compared (Fig. 5). As expected, a stronger reaction was obtained with increasing prepulse intensity, but this responsiveness was attenuated in the Fischer relative to Lewis animals. Amphetamine pretreatment, on the other hand, appeared to shift the response up across all prepulse conditions (including no-stimulus condition). This impression was confirmed by $2 \times 2 \times 4$ (strain $\times$ pretreatment $\times$ prepulse intensity) split-plot ANOVA across prepulse-alone and no-stimulus trials, which yielded a highly significant main effect of prepulse intensity $[F(3,132)=27.41, p<$ $0.001]$, and its interaction with strain $[F(3,132)=6.21, p<$ $0.001]$. The main effect of pretreatment also achieved statistical significance $[F(1,44)=4.08, p<0.05]$, but there was no evidence that this effect depended on prepulse intensity [pretreatment $\times$ prepulse intensity: $F<1$ ]. Pairwise comparisons between strains at successive prepulse intensity showed that Fischer rats showed higher baseline activity on no-stimulus trials $[p<0.05]$, but weaker response to the $+18-\mathrm{dB}$ prepulse stimulus $[p<0.05]$, in comparison to Lewis rats. Hence, there was some indication that the relative reduction in PPI expression revealed in the Fischer strain was accompanied by a relatively weaker prepulse-elicited response to the prepulse as seen in PPI disruption resulting from NMDA receptor blockade (see, Yee et al. 2004).

\section{Spontaneous object recognition}

Familiarity judgment was evaluated using a spontaneous object recognition memory test conducted in the open field arena on withdrawal days 48 and 49 . The sample phase (object familiarization) and the choice phase (test of novelty preference) were separately analyzed.

Sample phase Object exploration in the sample phase across the 2 days of testing was compared across days, instead of across delays (which was counterbalanced across days) because the delay interval took place only after the sample phase, and would not be expected to exert any influence on sample phase behavior. To this end, a $2 \times 2 \times$ $2 \times 5$ (strain $\times$ pretreatment $\times$ days $\times 1$-min bins) split-plot ANOVA of sample object exploration time (logarithmically transformed) was conducted. As shown in Fig. 6a, a clear habituation over the 5-min sample period was observed [bins: $F(4,172)=21.32, p<0.001]$, and this habituation effect was stronger in the Lewis than in the Fischer rats [strain $\times$ bins: $F(4,172)=4.67, p<0.005$; strain: $F(1,43)=$ $10.63, p<0.005]$. Pair-wise comparisons between strains at successive 1-min bins showed that object exploration time was significantly less $[p<0.05]$ in Lewis rats from bin 3 onwards (Fig. 6a).

A general reduction of object exploration was also apparent across days $[F(1,43)=5.74 ; p<0.05$; day $1=$ $12.40 \pm 0.16$, day $2=2.31 \pm 0.14]$, but this was not dissimilar between strains. Amphetamine pretreatment also resulted in a general reduction in sample exploration $[F$ $(1,43)=5.92 ; p<0.05$; Fig. $6 \mathrm{c}]$, but this pretreatment effect was not dependent on either days or rat strain.

Choice (test) phase Preferential exploration of the novel (non-sampled) object was evaluated by a direct comparison

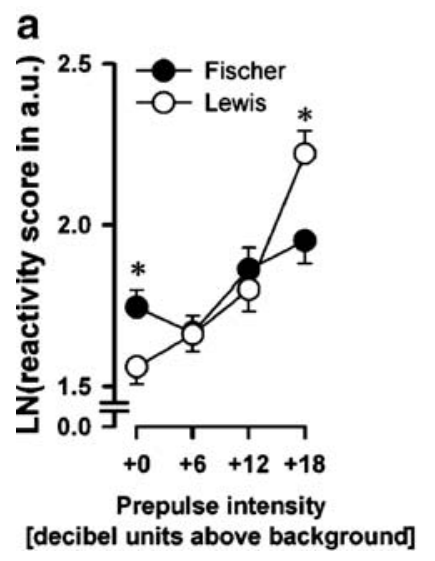

Fig. 5 Direct reaction in prepulse-alone trials. Reactivity to the prepulse-alone trials observed in the PPI test after 38 or 39 days of withdrawal in Fischer and Lewis rats pretreated with saline or amphetamine ( $N=12$ per strain per pretreatment). The direct reactivity to prepulse-alone trials is presented split by strains (a), by pretreatment (b), and by strain and by pretreatment (c). The Fischer rats showed increased baseline reactivity in the no-stimulus trials, but a weaker response to the $+18-\mathrm{dB}$ prepulse stimulus. Amphetamine
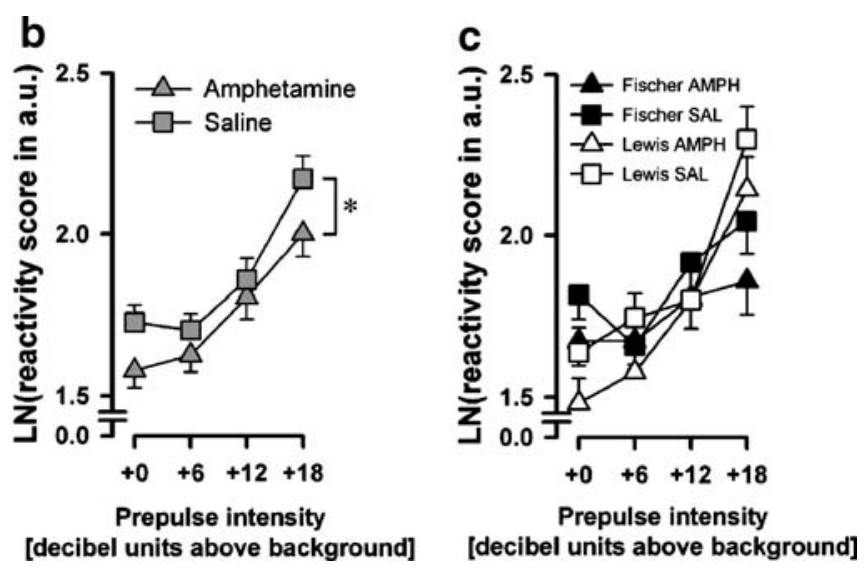

pretreatment resulted in decreased overall reactivity to prepulse-alone trials. All values are mean \pm standard error derived from the ANOVA. Asterisks in (a) refer to statistically significant difference between strains $(p<0.05)$ based on pair-wise comparisons at successive prepulse intensity conditions using the error variance associated with the significant strain by prepulse intensity interaction taken from the overall ANOVA; the asterisk in (b) denotes the overall main effect of pretreatment $(p<0.05)$ 


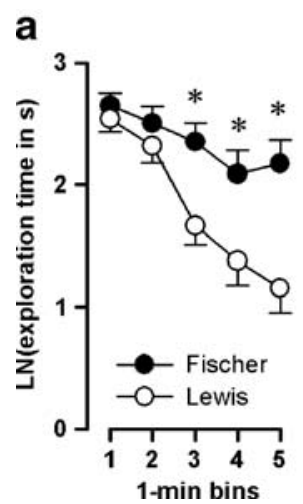

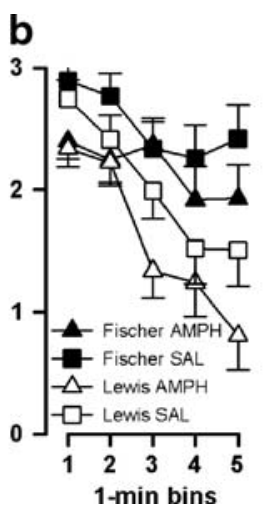

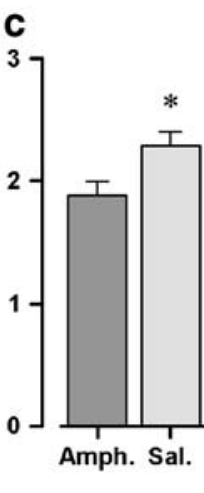

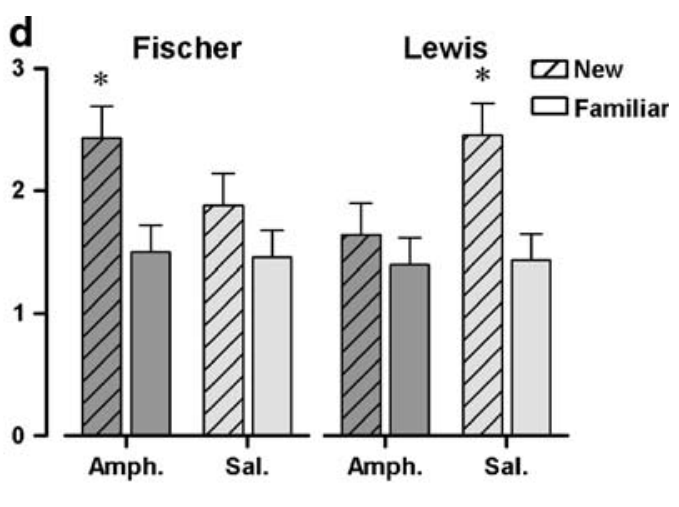

Fig. 6 Exploratorypair-wise comparisons between 'new' and 'familiar' object exploration time based on the strain $\times$ pretreatment $\times$ novelty interaction $(p<0.05)$ " were changed to "c" and "d", respectively. Please check if appropriate.?> behavior in the object recognition task. Logarithmic transformation of the exploration time in the object recognition test after 48 and 49 days of withdrawal in Fischer and Lewis rats pretreated with saline or amphetamine $(N=12$ per strain per pretreatment) for each 1-min bin of the sample phase split by strain (a) or by strain and by pretreatment (b), as total exploration time during the sample phase split by pretreatment (c), and for the test phase split by strain and by pretreatment (d). Fischer rats failed to show a similar habituation to Lewis rats in the sample phase. In addition, amphetamine pretreatment resulted in a slight but

between time spent exploring the familiar and novel objects by a $2 \times 2 \times 2 \times 2($ strain $\times$ pretreatment $\times$ delays $\times$ novelty) split-plot ANOVA of exploration time (logarithmically transformed). Delay refers to a within-subject factor counterbalanced across days, so the days factor was not included in this analysis. As shown in Fig. 6d, preference for the novel object was strengthened by amphetamine pretreatment in the Fischer rats, but weakened by the same treatment in Lewis rats. This contrast was already accompanied by a difference between strains in the salinepretreated animals: saline-pretreated Lewis rats exhibited a stronger novel object preference than saline-pretreated Fischer rats. Hence, amphetamine pretreatment effectively reversed the existing strain difference in performance. This interpretation of the data was confirmed by the critical strain $\times$ pretreatment $\times$ novelty interaction that just reached statistical significance $[F(1,44)=4.00, p=0.05]$. This was also accompanied by the presence of an overall novelty effect $[F(1,44)=16.22 ; p<0.001]$. There was, however, no indication that the contrast in delay intervals ( 2 vs. $15 \mathrm{~min}$ ) affected performance: neither the main effect of delay nor its interaction achieved statistical significance.

Spatial working memory test in the water maze

Spatial working memory function was evaluated using the Morris water maze across withdrawal days 50 to 55 . The platform location was varied across test sessions, but significant decrease in exploration. In the test phase, amphetamine pretreatment resulted in enhanced preference for the novel object in Fischer rats, and inversely, a reduction of preference for the novel object, in the Lewis rats. All values are mean \pm standard error derived from the ANOVA. Asterisks in (a) refer to statistical significant difference between strains $(p<0.05)$ based on pair-wise comparisons at successive 1-min bins using the error variance associated with the significant strain by bins interaction taken from the overall ANOVA; the asterisk in (c) denotes the significant main effect of pretreatment $(p<0.05)$, and in (d) the significant pair-wise comparisons between "new" and "familiar" object exploration time based on the strain $\times$ pretreatment $\times$ novelty interaction $(p<0.05)$

remained constant from trials 1 to 2 within a given session. Working memory function was therefore effectively indexed by improvement in escape from trials 1 to 2 . There were a total of ten sessions, with two sessions conducted per day (separated by $4 \mathrm{~h}$ in-between sessions on the same day). There was a systemic difference in swim speed between Lewis and Fischer rats in this test $[p<0.005]$, so we focused on the statistical analysis of path length measure (logarithmic transformation of path length in meters) instead of escape latency. However, analysis of escape latency yielded similar impressions in terms of performance change as a function of trials; and therefore the interpretation regarding working memory function was essentially independent of which of the two measures was examined.

Cued task All rats learned to escape from the water by climbing onto the platform when its location was indicated by the cue. There was an improvement in performance from trials 1 to 2 , as indicated by the presence of a highly significant main effect of trials $[F(1,44)=24.99, p<0.001]$ in a $2 \times 2 \times 2($ strain $\times$ pretreatment $\times$ trials $)$ split-plot ANOVA of path length (ln transformed path length in meters). The mean log-transformed path lengths from trials 1 to 2 were $2.23 \pm 0.12$ and $1.19 \pm 0.17$, respectively.

Working memory As shown in Fig. 7, improvement in performance as indicated by a reduction of escape path length from trials 1 to 2 was apparent in all groups except the saline-pretreated Fischer rats. However, the overall $2 \times 2 \times 5 \times$ 


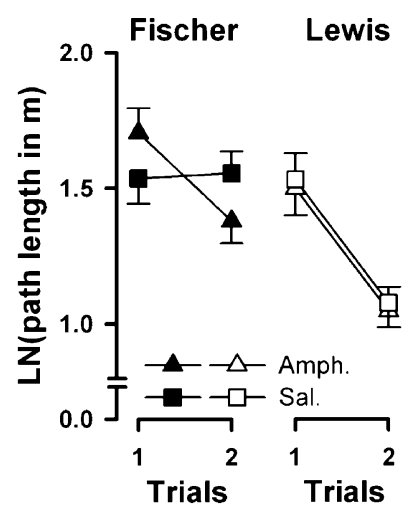

Fig. 7 Working memory in the Morris water maze. Logarithmic transformation of the path length in the Morris water maze in meters using the working memory protocol after 50-55 days of withdrawal in Fischer and Lewis rats pretreated with saline or amphetamine $(N=12$ per strain per pretreatment). Performance split by strain and by pretreatment for the five acquisition days. In the acquisition phase, Lewis rats showed a good performance independent of the pretreatment. Interestingly, in the Fischer rats, the saline group showed poor performance, whereas the amphetamine-pretreated animals showed a clear improvement between trials 1 and 2 . All values are mean \pm standard error derived from the ANOVA

$2 \times 2$ (strain $\times$ pretreatment $\times$ days $\times$ sessions $\times$ trials $)$ splitplot ANOVA for swim path length only revealed a significant main effect of strain $[F(1,44)=15.77, p<0.001]$ and of trials $[F(1,44)=23.27, p<0.001]$, but not the critical strain $\times$ pretreatment $\times$ trials interaction $[F(1,44)=1.89, p=$ $0.176]$ needed to support the specific impairment of working memory function in saline-pretreated Fischer rats. However, given the overall difference existing between strains, and the a priori decision to examine the presence of a pretreatment effect specific to each strain, supplementary restricted $2 \times 5 \times$
$2 \times 2$ (pretreatment $\times$ days $\times$ sessions $\times$ trials) ANOVAs confined to each rat strain were carried out. A significant pretreatment by trials interaction $[F(1,22)=4.33, p<0.05]$ was obtained in the Fischer rats, lending support to the interpretation that amphetamine pretreatment affected working memory performance in this rat strain. This interpretation is further supported by the presence of significant trials effect only in the amphetamine-pretreated $[F(1,11)=5.54, p<0.05]$ but not the saline-pretreated $[F<1]$ Fischer rats. On the other hand, the equivalent analysis restricted to the Lewis yielded no indication of any effect of amphetamine pretreatment, but only an overall effect of trials $[F(1,22)=22.88, p<0.001]$.

An identical pattern of results regarding working memory function was obtained based on the statistical analysis of escape latency (ln-transformed; data not shown).

\section{Behavioral sensitization}

The three phases of the experiment (baseline, saline, amphetamine) were conducted in the same activity boxes on withdrawal days 57 (baseline) and 58 (saline and amphetamine injections) and were separately analyzed and described below.

Baseline stage The baseline locomotor activity was measured during the last hour of the 18-h habituation period. The animals expressed a stable low locomotor activity throughout the $1-\mathrm{h}$ observation. There was no evidence for any significant strain difference, amphetamine pretreatment or 20 -min bins main effect in baseline locomotor activity based on a $2 \times 2 \times 3$ (strain $\times$ pretreatment $\times 20$-min bins) split-plot ANOVA (Fig. 8a). The interaction terms also did not attain significance.

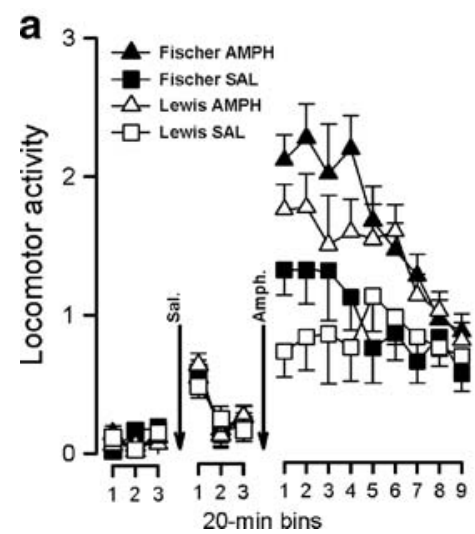

Fig. 8 Behavioral sensitization to an amphetamine challenge. Locomotor activity measured following an initial 18-h habituation period (only the last hour shown), a 1-h period following an injection of saline, and a 3-h period following a challenge injection of $1 \mathrm{mg} / \mathrm{kg}$ amphetamine on withdrawal day 59 presented by strain and by treatment (a). The locomotor response to the amphetamine challenge presented by strain (b) and by pretreatment (c). Fischer rats showed a transient increased locomotor activity compared to Lewis rats until the fourth 20-min bin (b). Amphetamine-pretreated rats exhibited
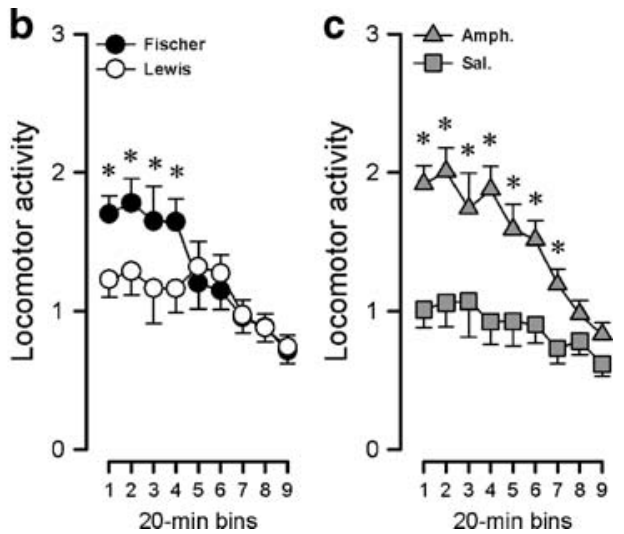

increased locomotor activity responses to the challenge during the first seven 20-min bins (c). All values refer to means \pm standard error derived from the ANOVA. Asterisks in (b) and (c) refer to a statistical difference between strains $(p<0.05)$ and between pretreatments $(p<$ $0.05)$, respectively, based on the appropriate pair-wise comparisons as successive bins, using the error variance associated with the significant strain by bins (b) and pretreatment by bins (c) interaction in the overall ANOVA 
Saline stage Following saline injection, locomotor activity was measured for a further hour. There was a transient increase in locomotor activity (Fig. 8a), and these impressions were supported by a $2 \times 2 \times 3($ strain $\times$ pretreatment $\times$ 20 -min bins) split-plot ANOVA of locomotor activity, which yielded a significant main effect of bins $[F(2,24)=$ 23.03, $p<0.001]$.

Amphetamine stage Following the amphetamine injection, locomotor activity was measured for $3 \mathrm{~h}$. All subjects showed an increase in locomotor activity in response to the amphetamine challenge that declined after $2 \mathrm{~h}$ (Fig. 8a). Fischer rats showed an increased initial locomotor activity and a higher peak response to the amphetamine challenge, returning to comparable levels to Lewis after the fourth 20-min bin (Fig. 8b). The amphetamine-pretreated rats showed an increased locomotor activity compared to the saline-pretreated rats during the $2 \mathrm{~h}$ following the amphetamine challenge (Fig. 8c). These impressions were supported by a $2 \times 2 \times 9$ (strain $\times$ pretreatment $\times 20$-min bins $)$ split-plot ANOVA of locomotor activity, which yielded a significant main effect of pretreatment $[F(1,12)=12.75$; $p<0.005]$, of bins $(F(8,96)=15.75 ; p<0.001]$, of pretreatment $\times$ bins interaction $[F(8,96)=4.09 ; p<0.001]$, and of strain $\times$ bins interaction $[F(8,96)=4.01 ; p<0.001]$. Pair-wise comparisons between pretreatment and strain at each successive bin yielded a significant pretreatment effect until the seventh bin and a significant strain effect until the fourth bin $[p<0.05]$.

\section{Discussion}

The present study aims to evaluate the impact of a sensitized dopamine system on cognitive performance in a unique design that utilizes a well-characterized comparison between Fischer and Lewis rats that markedly differ, among other traits, in the tests of memory function selected here. Under the non-sensitized (saline-pretreated) condition, Fischer rats exhibited substantial performance deficiency relative to Lewis rats in Pavlovian conditioning, spontaneous object recognition, and spatial working memory. In the latter two tasks, in particular, non-sensitized Fischer rats effectively failed to display any evidence of learning. These observations are largely in line with previous comparative studies of these two strains (Miserendino et al. 2003; Pryce et al. 1999). Such severe cognitive impairment in the Fischer rats contrasted sharply with their relatively mild deficiency in sensorimotor gating and the transient reduction in spontaneous locomotor activity under unchallenged condition observed in the open field test. Consideration of these baseline strain differences is essential to the interpre- tation of the behavioral cognitive effects of amphetamine pretreatment.

Sensitivity and sensitization to systemic amphetamine challenge

The presence of sensitization in the amphetamine-pretreated animals was confirmed at the end of the experimental series and was observed in both rat strains. In the absence of a statistically significant strain by pretreatment interaction, it is concluded that the functional sensitization achieved by the present amphetamine pretreatment regime was not dissimilar in the two strains. However, it should be noted that Fischer rats were more responsive during their first exposure to the drug. Given that the activity levels recorded during the baseline and saline phase of the assessment were highly comparable between strains, one suggestion would be that the dopamine neurotransmitter system in Fischer rats is more sensitive to the challenge of amphetamine (Brodkin et al. 1998; George et al. 1991; Miserendino et al. 2003; Stohr et al. 1998b). In addition, there are notable differences in mesolimbic dopamine axis reported between Fischer and Lewis rats, including alterations to dopamine physiology and metabolism in the ventral tegmental area and nucleus accumbens (e.g., Beitner-Johnson et al. 1991, 1992, 1993; Camp et al. 1994; Flores et al. 1998; Guitart et al. 1992, 1993; Strecker et al. 1995).

Taken together, there is ample evidence to suggest that an intrinsic strain difference in the sensitivity of the dopamine system existed prior to the sensitization treatment. Such differences in mesolimbic dopamine function are not only relevant to the divergent response between strains to acute amphetamine challenge seen in our nonsensitized animals (Di Chiara and Imperato 1988), but also to the divergent effects subsequently seen during amphetamine withdrawal and during the behavioral assessments of memory performance (see further discussion below).

The observed strain differences in the sensitivity to amphetamine may also be partially mediated by differences in the level in the hypothalamus-pituitary-adrenal system: Lewis rats have been shown to exhibit a deficient neuroendocrine response to stress (Dhabhar et al. 1993; Rivest and Rivier 1994). As an example, stress- or drug-induced corticosterone release is attenuated in Lewis compared to Fischer rats (Simar et al. 1996). Cador et al. suggested that rats with a high stress-induced corticosterone release show higher amphetamine-induced locomotion and are more likely to develop amphetamine self-administration (Cador et al. 1993).

Relevance beyond psychotic symptoms?

The critical evaluation here concerns whether amphetamineinduced sensitization produces dissimilar effects between 
strains. Our behavioral analyses have identified effects that are common to both strains, unique to one strain only, or act in incongruent directions between strains. The mnemonic effects of amphetamine-induced sensitization are among such straindependent effects. In comparison to their respective nonsensitized controls, sensitized Fischer rats exhibited notable improvement in object recognition as well as in spatial working memory. On the other hand, sensitized Lewis rats performed poorly relative to non-sensitized Lewis controls in the object recognition test. In contrast, Pavlovian conditioning was entirely insensitive to amphetamine pretreatment, even though the two strains also differed substantially in baseline performance, which was consistent with existing reports (e.g., Pryce et al. 1999). Two possible explanations for the increased freezing levels of the Lewis rats as compared to the Fischer rats were: (a) The Lewis strain is known to have poor acquisition of two way active avoidance (Katzev and Mills 1974; Stohr et al. 1998a), which is due to increased freezing levels; and (b) lower pain threshold in the Lewis strain rather than any difference in general anxiety response (as shown here) (Stohr et al. 1998a).

Altogether, these findings suggest that neither genetic background nor baseline performance difference alone could sufficiently account for the present data. Firstly, amphetamine pretreatment was not preferentially effective in one strain rather than in the other. Secondly, although baseline performance was generally lower in the Fischer rats, amphetamine pretreatment did not indiscriminately elevate performance in all cases: neither Pavlovian conditioning nor PPI expression in Fischer rats was responsive to amphetamine pretreatment. Similarly, amphetamine pretreatment did not indiscriminately lower performance in Lewis rats. From a different perspective, the experimental outcomes, therefore, do not readily suggest any direct resemblance to the cognitive deficits characteristic of schizophrenia. Instead, there was evidence that a sensitized dopamine system might facilitate working memory function - at least in the Fischer rats. Should one therefore conclude that the amphetamine sensitization model of schizophrenia bears little relevance to the cognitive symptoms of the disease?

\section{Prepulse inhibition}

We first consider the outcome of the PPI experiment because Geyer (2006) proposes that "although PPI cannot be considered to be a cognitive process per se, [its] abnormalities ... may be predictive of, or lead to, complex cognitive deficits". The PPI paradigm employed here has been shown to be sensitive to systemic apomorphine or dizocilpine (MK-801) treatment in rats (Pothuizen et al. 2006) and was able to detect the difference existing between Fischer and Lewis rats, yet it failed to reveal any effect of amphetamine pretreatment on PPI expression. This is somewhat surprising given that the efficacy of the present amphetamine pretreatment regime to produce PPI deficit has been previously demonstrated by Fletcher and colleagues although in another rat strain, namely SpragueDawley rats (Tenn et al. 2003, 2005). This discrepancy may likely reflect a strain-dependent sensitivity to this specific amphetamine treatment regime. Hence, at least in terms of PPI, an active regime identified in one strain of rats (even an outbred strain) may not readily generalize to other strains. We have previously demonstrated that a similar escalating amphetamine regime was without any effect on PPI expression in Wistar rats (Murphy et al. 2001; PelegRaibstein et al. 2006a; Russig et al. 2002, 2003, 2005). This apparent lack of consistency across rat strains specific to PPI may not be too surprising given that considerable divergence between strains also exists following acute pharmacological treatments (Swerdlow et al. 1998; Varty and Geyer 1998). Moreover, the present null results should not be taken as evidence that PPI expression in Fischer and Lewis rats is relatively insensitive to amphetamine-induced sensitization because they may respond to another schedule, as we have previously demonstrated in Wistar animals (Peleg-Raibstein et al. 2006a, b, 2008; Russig et al. 2005). It should be emphasized that such strain- and regimedependent effects on PPI are always reported against a clear presence of behavioral sensitization effect to a subsequent acute amphetamine challenge. Hence, additional experiments with other amphetamine pretreatment schedules and the inclusion of multiple strains would be warranted to fully interpret the relevance of the current null results in PPI.

At present, it would be prudent not to infer that our PPI results refute the hypothesis that sensitization of the dopamine system is without any effect on sensorimotor gating or related cognitive functions. Instead of relying on the proposed potential of PPI to index cognitive function, another obvious approach to examining the face validity of the amphetamine withdrawal model for schizophrenia cognitive deficiency is surely to employ tests that directly tax mnemonic functions.

\section{Inconsistent mnemonic effects}

Intriguingly, amphetamine withdrawal led to divergent effects on mnemonic functions between Fischer and Lewis rats. It improved performance in the working memory water maze test and object recognition in Fischer rats, but impaired object recognition memory in Lewis rats without affecting water maze performance.

In recreational users of methamphetamine and amphetamine, abstinence is associated with working memory deficit and right dorsolateral prefrontal cortex (PFC) activation (Ersche et al. 2006; McCann 2008). This may reflect a similar mechanism responsible for the poor 
working memory performance observed in schizophrenia, which is believed to stem from a deficiency in dorsolateral PFC dopaminergic function (Davis et al. 1991; Weinberger 1987). Studies in rats and primates have suggested that amphetamine withdrawal is associated with multiple significant changes in PFC dopaminergic function: reduced responsiveness to dopamine and $\mathrm{D}_{1}$ receptor agonist (Peterson et al. 2000, 2006), reduced dopamine turnover (Castner et al. 2005), and (compensatory) elevated PFC dopamine release during aversive classical conditioning (Peleg-Raibstein et al. 2008).

The modulation of working memory performance by PFC dopaminergic activity, however, is likely to follow an inverted U-shape function (see Fig. 9a): Deficits are reported when PFC dopaminergic signaling is either excessively enhanced or reduced, such that efficiency in performance falls below the optimal level (for a review, see Williams and Castner 2006).

Could the strain-dependent outcomes reflect known differences in dopaminergic functions between the two rat strains? Several lines of evidence suggest that the mesolimbic dopaminergic system may be more active in Fischer than Lewis rats. Fischer rats show a stronger expression of tyrosine hydroxylase and baseline dopamine metabolites in the nucleus accumbens compared with Lewis rats (BeitnerJohnson et al. 1991; Camp et al. 1994; Guitart et al. 1992; Ortiz et al. 1995). Indeed, we also showed here that (salinepretreated) Fischer rats were more responsive to the first exposure to amphetamine, and that PFC dopaminergic activation in response to stress is higher in Fischer than in

A

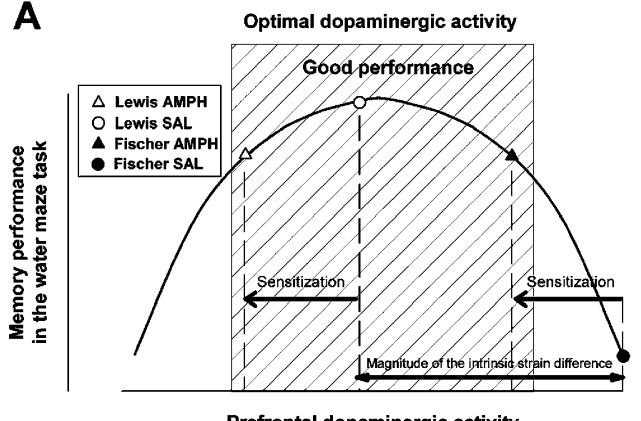

Prefrontal dopaminergic activity

Fig. 9 Impact of the different between-subject factors on the prefrontal dopaminergic function and the consequent influence on working memory performance. a The inverted U-shape curve of correspondence between prefrontal dopaminergic activity and memory performance in the water maze task. Lewis rats are known to present decreased dopaminergic activity compared to Fischer rats, and therefore have a shift to the left. Similarly, amphetamine sensitization has been shown to lead to a decrease in prefrontal dopaminergic activity and to a hypothetical decrease of the integrated mesolimbic dopaminergic projections on the perirhinal cortex, and consequently, sensitized animals are also shifted to the left of the curve. The four experimental groups, both Fischer and Lewis rats that were pretreated
Lewis rats (Lindley et al. 1999). This was sufficiently excessive to impair water maze learning in the salinepretreated Fischer rats, given the stressful nature of the water maze paradigm (see also Dalla et al. 2008; Del Arco and Mora 2001). Against this background, amphetamine withdrawal is expected to lead to a reduction (leftward shift) in prefrontal dopaminergic activity in both rat strains as depicted in Fig. 9a. It is therefore conceivable that this reduction returned the Fischer rats to a more favorable level of dopaminergic activity that benefited performance, while it was insufficient to significantly impair performance in Lewis rats because the reduction did not exceed the lower margin of the optimal range.

With a slight modification, this scheme may also account for the bidirectional effects of amphetamine withdrawal between strains observed in object recognition memory (Fig. 9b), although it is the perirhinal cortex that is more critically involved in object recognition (Steckler et al. 1998), and the contribution of the PFC cortex may only be limited to specific forms of object-in-place memory (Barker et al. 2007; Hannesson et al. 2004). However, the ascending dopaminergic inputs from the ventral tegmental area (a critical dopaminergic substrate of amphetamine sensitization: for a review, see Kalivas and Stewart 1991) also project to the perirhinal cortex and adjoining temporal structures (Deacon et al. 1983; McIntyre et al. 1996) and therefore may also assume a modulatory function over object recognition memory and/or novelty detection (e.g., Lisman and Grace 2005; McNab et al. 2009). This dopaminergic modulation may similarly follow an inverted

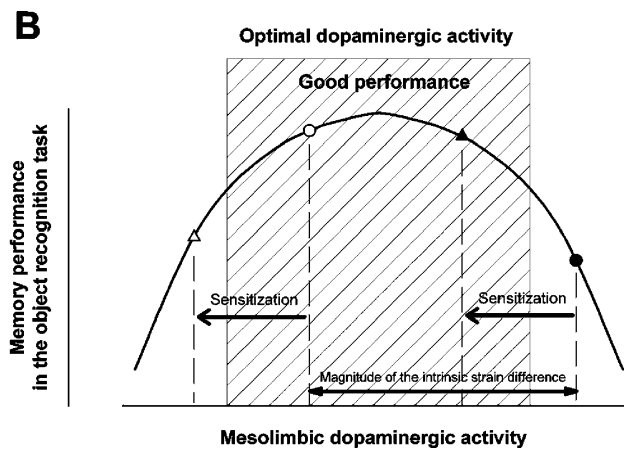

with either amphetamine or saline, were placed accordingly on the curve. b Similar inverted U-shape curve fitting for all four treatment groups, but for the relationship between mesolimbic dopaminergic levels and performance in the object recognition paradigm. The difference in terms of spread of the experimental group on the inverted U-shape curve originates from changes of modulatory structures and the increased dopaminergic activity resulting from the more stressful procedure in the water maze. Given the existence of multiple memory systems (as exemplified by the contrast between working memory and object recognition here), the possibility that each is associated with a distinct optimal dopaminergic modulation is an interesting and testable hypothesis that certainly warrants further investigation 
U-shaped profile. Given the intrinsic baseline difference in dopaminergic activity between Fisher and Lewis rats, it is also conceivable that a similar leftward shift in mesolimbic dopaminergic activity induced by amphetamine withdrawal improved performance in Fischer rats (by optimizing dopaminergic modulation) but impaired performance in Lewis rats (due to excessive reduction beyond the optimal range; Fig. 9b).

This scheme that takes into account baseline differences in dopaminergic activity, and the inverted U-shaped profile of dopaminergic modulation of cognitive processes may further accommodate data obtained in other rat strains, providing a possible parsimonious account for divergent outcomes. Furthermore, it may account for the relative efficacy of different amphetamine treatment regimes and their respective efficacy between strains in modifying cognitive functions.

Beyond strain-dependent validity

The present study has yielded only limited evidence that the amphetamine pretreatment schedule employed here might produce pronounced schizophrenia-like cognitive deficiency in either Fischer or Lewis rats. However, a conclusion that amphetamine withdrawal may not be a useful model beyond schizophrenia psychotic symptoms may be premature. We obtained significant effects on memory functions, albeit the direction of the effects clearly depended on rat strains. The unexpected findings of performance improvement seen in Fischer rats may be less surprising when one takes into account the unique inverted U-shaped profile of dopaminergic modulation over cognitive functions. Moreover, this is in line with some indications that acute amphetamine administration can improve cognitive functioning in medicated schizophrenia patients (Barch and Carter 2005; Goldberg et al. 1991; Kirrane et al. 2000). Hence, there is certainly value in further examining the neural basis of amphetamine withdrawal — not only in terms of its face validity (in producing schizophrenia-like cognitive deficits) but also its construct validity in relation to modeling the disease mechanisms as well as potential therapeutic avenues. In this respect, the use of multiple inbred rat strains may be particularly useful.

Here, we showed that the choice of strains can be as important as the precise amphetamine treatment schedule employed in determining the ultimate impact on cognition. There has been considerable debate between laboratories as to the relative efficacy of different amphetamine withdrawal schedules. The present study exemplifies that although this schedule has been shown to be capable in inducing some cognitive deficits in outbred Sprague-Dawley rats (Fletcher et al. 2005, 2007; Tenn et al. 2005), this finding may not be readily generalized to other rat strains. By choosing inbred rats, one reduces the strain variability and genetic heterogeneity against a reproducible and definable difference in genetic background. When divergent effects emerge as shown here, the results can be further examined in terms of genetic propensity or vulnerability to the development of schizophrenia-like psychopathology (under a specific environmental challenge as defined, for example, by an amphetamine treatment schedule). Such an approach would enhance the construct validity of the model and lead eventually to the specification of animal models with more robust face validity as well as predictive validity.

Acknowledgments The present study was supported by the Swiss Federal Institute of Technology (ETH) Zurich. The authors are also grateful to Peter Schmid for his excellent technical support, to Tamaki Bieri, Stéphanie McGarrity, Michel Schaffner, Felix Schlegel, Monika Seps, Ronald Vogel, and Tianbuo Yao for technical assistance, and to the animal husbandry staff at the Laboratory of Behavioral Neurobiology for their maintenance of the subjects used in the experiments.

\section{References}

Abi-Dargham A, Gil R, Krystal J, Baldwin RM, Seibyl JP, Bowers M, van Dyck CH, Charney DS, Innis RB, Laruelle M (1998) Increased striatal dopamine transmission in schizophrenia: confirmation in a second cohort. Am J Psychiatry 155:761-767

Abi-Dargham A, Rodenhiser J, Printz D, Zea-Ponce Y, Gil R, Kegeles LS, Weiss R, Cooper TB, Mann JJ, Van Heertum RL, Gorman JM, Laruelle M (2000) Increased baseline occupancy of D2 receptors by dopamine in schizophrenia. Proc Natl Acad Sci U S A 97:8104-8109

Alexander RC, Wright R, Freed W (1996) Quantitative trait loci contributing to phencyclidine-induced and amphetamine-induced locomotor behavior in inbred mice. Neuropsychopharmacology 15:484-490

Barch DM, Carter CS (2005) Amphetamine improves cognitive function in medicated individuals with schizophrenia and in healthy volunteers. Schizophr Res 77:43-58

Barker GR, Bird F, Alexander V, Warburton EC (2007) Recognition memory for objects, place, and temporal order: a disconnection analysis of the role of the medial prefrontal cortex and perirhinal cortex. J Neurosci 27:2948-2957

Beitner-Johnson D, Guitart X, Nestler EJ (1991) Dopaminergic brain reward regions of Lewis and Fischer rats display different levels of tyrosine hydroxylase and other morphine- and cocaineregulated phosphoproteins. Brain Res 561:147-150

Beitner-Johnson D, Guitart X, Nestler EJ (1992) Common intracellular actions of chronic morphine and cocaine in dopaminergic brain reward regions. Ann N Y Acad Sci 654:70-87

Beitner-Johnson D, Guitart X, Nestler EJ (1993) Glial fibrillary acidic protein and the mesolimbic dopamine system: regulation by chronic morphine and Lewis-Fischer strain differences in the rat ventral tegmental area. J Neurochem 61:1766-1773

Braff DL, Light GA (2004) Preattentional and attentional cognitive deficits as targets for treating schizophrenia. Psychopharmacology (Berl) 174:75-85

Breier A, Su TP, Saunders R, Carson RE, Kolachana BS, de Bartolomeis A, Weinberger DR, Weisenfeld N, Malhotra AK, Eckelman WC, Pickar D (1997) Schizophrenia is associated with elevated amphetamine-induced synaptic dopamine concentra- 
tions: evidence from a novel positron emission tomography method. Proc Natl Acad Sci U S A 94:2569-2574

Brodkin ES, Carlezon WA Jr, Haile CN, Kosten TA, Heninger GR, Nestler EJ (1998) Genetic analysis of behavioral, neuroendocrine, and biochemical parameters in inbred rodents: initial studies in Lewis and Fischer 344 rats and in A/J and C57BL/6 J mice. Brain Res 805:55-68

Cador M, Dulluc J, Mormede P (1993) Modulation of the locomotor response to amphetamine by corticosterone. Neuroscience 56:981-988

Camp DM, Browman KE, Robinson TE (1994) The effects of methamphetamine and cocaine on motor behavior and extracellular dopamine in the ventral striatum of Lewis versus Fischer 344 rats. Brain Res 668:180-193

Castner SA, Vosler PS, Goldman-Rakic PS (2005) Amphetamine sensitization impairs cognition and reduces dopamine turnover in primate prefrontal cortex. Biol Psychiatry 57:743-751

Dalla C, Antoniou K, Kokras N, Drossopoulou G, Papathanasiou G, Bekris S, Daskas S, Papadopoulou-Daifoti Z (2008) Sex differences in the effects of two stress paradigms on dopaminergic neurotransmission. Physiol Behav 93:595-605

Davis KL, Kahn RS, Ko G, Davidson M (1991) Dopamine in schizophrenia: a review and reconceptualization. Am J Psychiatry 148:1474-1486

Deacon TW, Eichenbaum H, Rosenberg P, Eckmann KW (1983) Afferent connections of the perirhinal cortex in the rat. J Comp Neurol 220:168-190

Del Arco A, Mora F (2001) Dopamine release in the prefrontal cortex during stress is reduced by the local activation of glutamate receptors. Brain Res Bull 56:125-130

Dhabhar FS, McEwen BS, Spencer RL (1993) Stress response, adrenal steroid receptor levels and corticosteroid-binding globulin levels - a comparison between Sprague-Dawley, Fischer 344 and Lewis rats. Brain Res 616:89-98

Di Chiara G, Imperato A (1988) Drugs abused by humans preferentially increase synaptic dopamine concentrations in the mesolimbic system of freely moving rats. Proc Natl Acad Sci U S A 85:5274-5278

Elvevag B, Goldberg TE (2000) Cognitive impairment in schizophrenia is the core of the disorder. Crit Rev Neurobiol 14:1-21

Ersche KD, Clark L, London M, Robbins TW, Sahakian BJ (2006) Profile of executive and memory function associated with amphetamine and opiate dependence. Neuropsychopharmacology 31:1036-1047

Featherstone RE, Rizos Z, Kapur S, Fletcher PJ (2008) A sensitizing regimen of amphetamine that disrupts attentional set-shifting does not disrupt working or long-term memory. Behav Brain Res 189:170-179

Feldon J, Weiner I (1992) From an animal model of an attentional deficit towards new insights into the pathophysiology of schizophrenia. J Psychiatr Res 26:345-366

Fletcher PJ, Tenn CC, Rizos Z, Lovic V, Kapur S (2005) Sensitization to amphetamine, but not $\mathrm{PCP}$, impairs attentional set shifting: reversal by a $D(1)$ receptor agonist injected into the medial prefrontal cortex. Psychopharmacology (Berl) 183:190-200

Fletcher PJ, Tenn CC, Sinyard J, Rizos Z, Kapur S (2007) A sensitizing regimen of amphetamine impairs visual attention in the 5-choice serial reaction time test: reversal by a D1 receptor agonist injected into the medial prefrontal cortex. Neuropsychopharmacology 32:1122-1132

Flores G, Wood GK, Barbeau D, Quirion R, Srivastava LK (1998) Lewis and Fischer rats: a comparison of dopamine transporter and receptors levels. Brain Res 814:34-40

George FR, Porrino LJ, Ritz MC, Goldberg SR (1991) Inbred rat strain comparisons indicate different sites of action for cocaine and amphetamine locomotor stimulant effects. Psychopharmacology (Berl) 104:457-462
Geyer MA (2006) The family of sensorimotor gating disorders: comorbidities or diagnostic overlaps? Neurotox Res 10:211-220

Geyer MA, Krebs-Thomson K, Braff DL, Swerdlow NR (2001) Pharmacological studies of prepulse inhibition models of sensorimotor gating deficits in schizophrenia: a decade in review. Psychopharmacology (Berl) 156:117-154

Gold JM, Carpenter C, Randolph C, Goldberg TE, Weinberger DR (1997) Auditory working memory and Wisconsin Card Sorting Test performance in schizophrenia. Arch Gen Psychiatry 54:159-165

Goldberg TE, Bigelow LB, Weinberger DR, Daniel DG, Kleinman JE (1991) Cognitive and behavioral effects of the coadministration of dextroamphetamine and haloperidol in schizophrenia. Am J Psychiatry 148:78-84

Goldberg TE, Patterson KJ, Taqqu Y, Wilder K (1998) Capacity limitations in short-term memory in schizophrenia: tests of competing hypotheses. Psychol Med 28:665-673

Goldberg TE, Weinberger DR, Berman KF, Pliskin NH, Podd MH (1987) Further evidence for dementia of the prefrontal type in schizophrenia? A controlled study of teaching the Wisconsin Card Sorting Test. Arch Gen Psychiatry 44:1008-1014

Goldman-Rakic PS (1994) Working memory dysfunction in schizophrenia. J Neuropsychiatry Clin Neurosci 6:348-357

Gray JA, Feldon J, Rawlins JNP, Smith AD, Hemsley DR (1991) The neuropsychology of schizophrenia. Behav Brain Sci 14:1-84

Green MF (2006) Cognitive impairment and functional outcome in schizophrenia and bipolar disorder. J Clin Psychiatry 67:38 discussion 36-42

Green MF, Nuechterlein KH (1999) Should schizophrenia be treated as a neurocognitive disorder? Schizophr Bull 25:309-319

Guitart X, Beitner-Johnson D, Marby DW, Kosten TA, Nestler EJ (1992) Fischer and Lewis rat strains differ in basal levels of neurofilament proteins and their regulation by chronic morphine in the mesolimbic dopamine system. Synapse 12:242-253

Guitart X, Kogan JH, Berhow M, Terwilliger RZ, Aghajanian GK, Nestler EJ (1993) Lewis and Fischer rat strains display differences in biochemical, electrophysiological and behavioral parameters: studies in the nucleus accumbens and locus coeruleus of drug naive and morphine-treated animals. Brain Res 611:7-17

Hannesson DK, Howland JG, Phillips AG (2004) Interaction between perirhinal and medial prefrontal cortex is required for temporal order but not recognition memory for objects in rats. J Neurosci 24:4596-4604

Kalivas PW, Sorg BA, Hooks MS (1993) The pharmacology and neural circuitry of sensitization to psychostimulants. Behav Pharmacol 4:315-334

Kalivas PW, Stewart J (1991) Dopamine transmission in the initiation and expression of drug- and stress-induced sensitization of motor activity. Brain Res Brain Res Rev 16:223-244

Katzev RD, Mills SK (1974) Strain differences in avoidance conditioning as a function of the classical CS-US contingency. J Comp Physiol Psychol 87:661-671

Kirrane RM, Mitropoulou V, Nunn M, New AS, Harvey PD, Schopick F, Silverman J, Siever LJ (2000) Effects of amphetamine on visuospatial working memory performance in schizophrenia spectrum personality disorder. Neuropsychopharmacology 22:14-18

Kolb B, Gorny G, Li Y, Samaha AN, Robinson TE (2003) Amphetamine or cocaine limits the ability of later experience to promote structural plasticity in the neocortex and nucleus accumbens. Proc Natl Acad Sci U S A 100:10523-10528

Kosten TA, Ambrosio E (2002) HPA axis function and drug addictive behaviors: insights from studies with Lewis and Fischer 344 inbred rats. Psychoneuroendocrinology 27:35-69

Laruelle M (1998) Imaging dopamine transmission in schizophrenia. A review and meta-analysis. Q J Nucl Med 42:211-221 
Laruelle M (2000) The role of endogenous sensitization in the pathophysiology of schizophrenia: implications from recent brain imaging studies. Brain Res Brain Res Rev 31:371-384

Lieberman JA, Sheitman BB, Kinon BJ (1997) Neurochemical sensitization in the pathophysiology of schizophrenia: deficits and dysfunction in neuronal regulation and plasticity. Neuropsychopharmacology 17:205-229

Lindley SE, Bengoechea TG, Wong DL, Schatzberg AF (1999) Strain differences in mesotelencephalic dopaminergic neuronal regulation between Fischer 344 and Lewis rats. Brain Res 832:152-158

Lisman JE, Grace AA (2005) The hippocampal-VTA loop: controlling the entry of information into long-term memory. Neuron 46:703-713

McCann DJ (2008) Potential of buprenorphine/naltrexone in treating polydrug addiction and co-occurring psychiatric disorders. Clin Pharmacol Ther 83:627-630

McIntyre DC, Kelly ME, Staines WA (1996) Efferent projections of the anterior perirhinal cortex in the rat. J Comp Neurol 369:302-318

McNab F, Varrone A, Farde L, Jucaite A, Bystritsky P, Forssberg H, Klingberg T (2009) Changes in cortical dopamine D1 receptor binding associated with cognitive training. Science 323:800-802

Miserendino MJ, Haile CN, Kosten TA (2003) Strain differences in response to escapable and inescapable novel environments and their ability to predict amphetamine-induced locomotor activity. Psychopharmacology (Berl) 167:281-290

Murphy CA, Fend M, Russig H, Feldon J (2001) Latent inhibition, but not prepulse inhibition, is reduced during withdrawal from an escalating dosage schedule of amphetamine. Behav Neurosci 115:1247-1256

Nestler EJ (2001) Molecular basis of long-term plasticity underlying addiction. Nat Rev Neurosci 2:119-128

Ortiz J, DeCaprio JL, Kosten TA, Nestler EJ (1995) Strain-selective effects of corticosterone on locomotor sensitization to cocaine and on levels of tyrosine hydroxylase and glucocorticoid receptor in the ventral tegmental area. Neuroscience 67:383-397

Pantelis C, Barber FZ, Barnes TR, Nelson HE, Owen AM, Robbins TW (1999) Comparison of set-shifting ability in patients with chronic schizophrenia and frontal lobe damage. Schizophr Res 37:251-270

Pantelis C, Harvey CA, Plant G, Fossey E, Maruff P, Stuart GW, Brewer WJ, Nelson HE, Robbins TW, Barnes TR (2004) Relationship of behavioural and symptomatic syndromes in schizophrenia to spatial working memory and attentional setshifting ability. Psychol Med 34:693-703

Paulson PE, Camp DM, Robinson TE (1991) Time course of transient behavioral depression and persistent behavioral sensitization in relation to regional brain monoamine concentrations during amphetamine withdrawal in rats. Psychopharmacology (Berl) 103:480-492

Peleg-Raibstein D, Knuesel I, Feldon J (2008) Amphetamine sensitization in rats as an animal model of schizophrenia. Behav Brain Res 191:190-201

Peleg-Raibstein D, Sydekum E, Feldon J (2006b) Differential effects on prepulse inhibition of withdrawal from two different repeated administration schedules of amphetamine. Int J Neuropsychopharmacol 9:737-749

Peleg-Raibstein D, Sydekum E, Russig H, Feldon J (2006a) Withdrawal from repeated amphetamine administration leads to disruption of prepulse inhibition but not to disruption of latent inhibition. J Neural Transm 113:1323-1336

Peterson JD, Wolf ME, White FJ (2000) Altered responsiveness of medial prefrontal cortex neurons to glutamate and dopamine after withdrawal from repeated amphetamine treatment. Synapse 36:342-344

Peterson JD, Wolf ME, White FJ (2006) Repeated amphetamine administration decreases D1 dopamine receptor-mediated inhibition of voltage-gated sodium currents in the prefrontal cortex. J Neurosci 26:3164-3168
Pothuizen HH, Neumann KR, Feldon J, Yee BK (2006) Selective nucleus accumbens core lesions enhance dizocilpine-induced but not apomorphine-induced disruption of prepulse inhibition in rats. Behav Pharmacol 17:107-117

Pryce CR, Lehmann J, Feldon J (1999) Effect of sex on fear conditioning is similar for context and discrete CS in Wistar, Lewis and Fischer rat strains. Pharmacol Biochem Behav 64:753-759

Richmond MA, Murphy CA, Pouzet B, Schmid P, Rawlins JN, Feldon J (1998) A computer controlled analysis of freezing behaviour. J Neurosci Methods 86:91-99

Rivest S, Rivier C (1994) Stress and interleukin-1 beta-induced activation of c-fos, NGFI-B and CRF gene expression in the hypothalamic PVN: comparison between Sprague-Dawley, Fisher-344 and Lewis rats. J Neuroendocrinol 6:101-117

Robinson TE, Becker JB (1986) Enduring changes in brain and behavior produced by chronic amphetamine administration: a review and evaluation of animal models of amphetamine psychosis. Brain Res 396:157-198

Russig H, Durrer A, Yee BK, Murphy CA, Feldon J (2003) The acquisition, retention and reversal of spatial learning in the Morris water maze task following withdrawal from an escalating dosage schedule of amphetamine in Wistar rats. Neuroscience 119:167-179

Russig H, Murphy CA, Feldon J (2002) Clozapine and haloperidol reinstate latent inhibition following its disruption during amphetamine withdrawal. Neuropsychopharmacology 26:765-777

Russig H, Murphy CA, Feldon J (2005) Behavioural consequences of withdrawal from three different administration schedules of amphetamine. Behav Brain Res 165:26-35

Simar MR, Saphier D, Goeders NE (1996) Differential neuroendocrine and behavioral responses to cocaine in Lewis and Fischer rats. Neuroendocrinology 63:93-100

Sokolov BP, Polesskaya OO, Uhl GR (2003) Mouse brain gene expression changes after acute and chronic amphetamine. J Neurochem 84:244-252

Steckler T, Drinkenburg WH, Sahgal A, Aggleton JP (1998) Recognition memory in rats-II. Neuroanatomical substrates. Prog Neurobiol 54:313-332

Stefani MR, Moghaddam B (2002) Effects of repeated treatment with amphetamine or phencyclidine on working memory in the rat. Behav Brain Res 134:267-274

Stohr T, Schulte Wermeling D, Szuran T, Pliska V, Domeney A, Welzl H, Weiner I, Feldon J (1998a) Differential effects of prenatal stress in two inbred strains of rats. Pharmacol Biochem Behav 59:799-805

Stohr T, Schulte Wermeling D, Weiner I, Feldon J (1998b) Rat strain differences in open-field behavior and the locomotor stimulating and rewarding effects of amphetamine. Pharmacol Biochem Behav 59:813-818

Stohr T, Szuran T, Welzl H, Pliska V, Feldon J, Pryce CR (2000) Lewis/Fischer rat strain differences in endocrine and behavioural responses to environmental challenge. Pharmacol Biochem Behav 67:809-819

Strecker RE, Eberle WF, Ashby CR Jr (1995) Extracellular dopamine and its metabolites in the nucleus accumbens of Fischer and Lewis rats: basal levels and cocaine-induced changes. Life Sci 56:PL135-PL141

Swerdlow NR, Martinez ZA, Hanlon FM, Platten A, Farid M, Auerbach P, Braff DL, Geyer MA (2000) Toward understanding the biology of a complex phenotype: rat strain and substrain differences in the sensorimotor gating-disruptive effects of dopamine agonists. J Neurosci 20:4325-4336

Swerdlow NR, Varty GB, Geyer MA (1998) Discrepant findings of clozapine effects on prepulse inhibition of startle: is it the route or the rat? Neuropsychopharmacology 18:50-56

Tenn CC, Fletcher PJ, Kapur S (2003) Amphetamine-sensitized animals show a sensorimotor gating and neurochemical abnormality similar to that of schizophrenia. Schizophr Res 64:103-114 
Tenn CC, Kapur S, Fletcher PJ (2005) Sensitization to amphetamine, but not phencyclidine, disrupts prepulse inhibition and latent inhibition. Psychopharmacology (Berl) 180:366-376

van der Staay FJ, Blokland A (1996) Behavioral differences between outbred Wistar, inbred Fischer 344, brown Norway, and hybrid Fischer 344 x brown Norway rats. Physiol Behav 60:97-109

Varty GB, Geyer MA (1998) Effects of isolation rearing on startle reactivity, habituation, and prepulse inhibition in male Lewis, Sprague-Dawley, and Fischer F344 rats. Behav Neurosci 112:1450-1457

Weinberger DR (1987) Implications of normal brain development for the pathogenesis of schizophrenia. Arch Gen Psychiatry 44:660-669

Weinberger DR, Gallhofer B (1997) Cognitive function in schizophrenia. Int Clin Psychopharmacol 12:S29-S36
Williams GV, Castner SA (2006) Under the curve: critical issues for elucidating D1 receptor function in working memory. Neuroscience 139:263-276

Wolf ME (2003) Effects of psychomotor stimulants on glutamate receptor expression. Methods Mol Med 79:13-31

Wong DF, Wagner HN Jr, Tune LE, Dannals RF, Pearlson GD, Links JM, Tamminga CA, Broussolle EP, Ravert HT, Wilson AA, Toung JK, Malat J, Williams JA, O'Tuama LA, Snyder SH, Kuhar MJ, Gjedde A (1986) Positron emission tomography reveals elevated D2 dopamine receptors in drug-naive schizophrenics. Science 234:1558-1563

Yee BK, Chang DL, Feldon J (2004) The effects of dizocilpine and phencyclidine on prepulse inhibition of the acoustic startle reflex and on prepulse-elicited reactivity in C57BL6 mice. Neuropsychopharmacology 29:1865-1877 